\title{
Mineralizaciones asociadas al Plutón Tocota. Sector Sur del Batolito de Colangüil, Cordillera Frontal, San Juan, Argentina.
}

\author{
Aníbal F. Wetten \\ Instituto de Investigaciones Mineras \\ Av. San Martín 1109 (O), 5400 - San Juan, Argentina. \\ Tel 5492644231700 e-mail: awetten@unsj.edu.ar
}

\begin{abstract}
RESUMEN
La porción austral del Batolito de Colangüil está representada por el plutón Tocota, de edad Pérmico, que intruye areniscas de edad Carbonífero tardío-Pérmico (Asselianense). Además, en dicha región, afloran cuerpos subvolcánicos de composición andesítica, tobas de edad Cenozoico, depósitos de piedemonte y rellenos aluviales y glaciares.

La región exhibe un conjunto de depósitos metalíferos de Cu-Au-As y ocasionalmente bismuto. Éstos comúnmente son filonianos y están asociados espacialmente a granodioritas, granitos y areniscas. Su desarrollo se interpreta perteneciente al ciclo Gondwánico.

Dentro de las rocas graníticas, las mineralizaciones se formaron entre $139{ }^{\circ} \mathrm{C}$ y aproximadamente $400{ }^{\circ} \mathrm{C}$, probablemente con posterioridad a la consolidación del plutón Tocota y mediante la circulación de fluidos hidrotermales, probablemente mezclados con aguas meteóricas. En la roca encajante, la mineralización ocurrió en un rango de temperaturas entre $250^{\circ} \mathrm{C}-350^{\circ} \mathrm{C}$, mediante actividad hidrotermal detectada por presencia de alteración fílica-argílica. La ganga está constituida mayoritariamente por cuarzo, turmalina y en ocasiones por feldespato potásico y calcita.

El patrón de distribución de la mineralización, tanto en las rocas graníticas como en las areniscas, consiste en: 1) relleno de fallas y diaclasas con predominio de las direcciones ENE y ONO, 2) brechas de falla y brechas por actividad hidrotermal y 3 ) diques de composición andesítica con bajos contenidos metálicos. La mineralización en la roca encajante comúnmente se manifiesta por relleno de fracturas, como así también diseminada en la roca, con intensa silicificación asociada.

Tales depósitos contienen minerales hipogénicos cuyas relaciones isotópicas ${ }^{34} \mathrm{~S} /{ }^{22} \mathrm{~S}$ serían compatibles con una filiación granítica, aunque no se pueden descartar otras procedencias.
\end{abstract}

Palabras claves: Ciclo Gondwánico, granito, hidrotermalismo, mineralizaciones, Plutón Tocota

\section{Mineralizations related to the Tocota pluton. Southern Colangüil batholith, Cordillera Frontal, San Juan, Argentina.}

\begin{abstract}
The southern portion of the Colangüil Batholith is formed by units of the Tocota Pluton, of Permian age, which intrude late Carboniferous-Permian (Asselian) sandstones. Sub-volcanic bodies with andesitic composition and tuffs of Cenozoic age, modern layers of piedmont sediments and both alluvial and glacier deposits also crop out. The region exhibits a set of metalliferous deposits (Cu-Au-As) and occasionally with bismuth. These are mostly filonian type. These are spatially associated with granodiorites, granite and sandstone. Their development is interpreted as belonging to the Gondwanan cycle.

Within granitic rocks, mineralizations were formed between $139{ }^{\circ} \mathrm{C}$ and about $400{ }^{\circ} \mathrm{C}$, probably after the consolidation of the Tocota pluton and by the upward circulation of hydrothermal fluids, probably mixed with meteoric waters. In the host rock, mineralization occurred in an interval between $200^{\circ} \mathrm{C}$ and $350{ }^{\circ} \mathrm{C}$, through hydrothermal activity detected in areas of phyllic-argillic alteration. The gangue constitutes mainly of quartz, tourmaline and sometimes potassium feldspar and calcite.
\end{abstract}


The mineralization pattern, in both the pluton and the sandstone, has been controlled by 1) a strong domain of ore filled faults and joints, with ENE and WNW as the more common strikes and NNW subordinated, 2) fault breccias and hydrothermal breccias, and 3) dykes of andesite composition with low metal content. The host rock mineralization is commonly emplaced in joints as well as finely disseminated, related to intense silicification.

Such deposits contain hypogene minerals whose isotopic ${ }^{34} S^{\beta 2} S$ ratios are compatible with a granite-like filiation but other provenances cannot be ruled out.

Key words: Gondwanan cycle; granite; hydrothermalism; mineralizations, Tocota Pluton

\section{Introduction and methodology}

This study is aimed at defining geological - mining characteristics of the southern portion of the Colangüil Batholith which is located in the eastern edge of the Cordillera Frontal (Fig. 1), with the purpose of characterizing the neopaleozoic sequence of mineralization, using the geological - textural pattern of recognized metallic substances, as well as defining the paragenesis of mineral deposits and hydrothermal processes, which were involved in the cited region and their possible metallogenic relationship.

The study sector is located in the province of San Juan (central-western Argentina), in the departments of Iglesia and Calingasta. It extends between the vicinities of the northern Tocota drainage $\left(69^{\circ} 25^{\prime} \mathrm{W}\right.$; $\left.30^{\circ} 35^{\prime} \mathrm{S}\right)$ and the Castaño river $\left(69^{\circ} 35^{\prime} \mathrm{W} ; 30^{\circ} 50^{\prime} \mathrm{S}\right)$ (Figs. 2 y 3).

Different geochemical zones were surveyed in the Tocota pluton and its surroundings to complement geologic data as well as to obtain support data for further prospection (Fig. 4).

For mapping tasks, LandsatTM images were used. TM 7-4-1 and 7-4-2 bands were employed for regional surveying of lithologies, the ratios 5/7, 5/4, 3/1 (RGB) for colour anomalies and directional filters for identification of structural alignments. Some analytical techniques were used to identify the mineralogical species, amongst which is the X-ray diffractometer (GEA - University of Concepción, Chile). Moreover, the associations of fluid inclusions and the homogenization/cooling temperatures were identified and measured, respectively. These specific activities were carried out in the Institute of Applied Economic Geology (University of Concepción, Chile) and in the USGS in Denver (CO).

The survey of the geochemical data began with the consideration of a background of previous research tasks on the ancient mines of the region.

Lithogeochemical sampling was then programmed. Three samples were obtained in zones located northeast and south of the zone 4 (Tocota district) and 45 inside zone 4. Chips of rock were collected from outcrops with hydrothermal alteration. On tabular structures, a cross-channel sampling was carried out. In the chemical results tables, geological, the mining and topographical references are cited rather than adding a location map of the samples (Tables 1, 2, 3).

The organization of the chemical analyses was based on the following aspects: type and mineral con- tent of substances already exploited, pathfinders of economic interest, elements of granite affinity as well as others that are usually included in the plasma analysis scan (ICP).

Gravimetric and atomic absorption (A.A.) methods were used for testing $\mathrm{Au}$ and $\mathrm{Ag}$ (Table 1). Other elements such as $\mathrm{Cu}, \mathrm{Pb}, \mathrm{Zn}, \mathrm{Mo}, \mathrm{As}$, Sb (volatile), $\mathrm{Mn}, \mathrm{Fe}$ and La, amongst others, were also analyzed by A.A. and ICP-OES. The detection limits of these elements ranked from 0.5 to $50 \mathrm{ppm}$ (Table 2).

The geochemically anomalous zones, in the environment of the Tocota pluton (Fig. 4), were delimited when considering both the analytical results that, as they were so high, may have an economic meaning as well as those values that exceeded the averages and ranges of the different background values in common igneous and sedimentary rocks (Hawkes and Webb, 1962).

\section{Results and discussion}

The studied metalliferous deposits can be assigned to the Gondwanan and the Andean magmatic cycles of Carboniferous to Permian-Triassic and Neogene, respectively (Malvicini and Caminos, 1994). The former has clear exponents in the study area, with particular paragenesis in both the Cerro Agua Negra Formation and the Tocota pluton. The Andean ore deposits have their manifestations of economic interest more towards the north, in the Chita stream, where volcanic bodies crop out (Fig. 2).

The units of the Tocota pluton and the neopaleozoic sandstones of Cerro Agua Negra Formation are carriers of particular metalliferous substances. The plutonic units exhibit the main metallic mines in the area of La Fragüita. Cu, Au and some Fe were exploited through shallow galleries and chutes (Table 3, Figs. 4, 5 and 7-a). These mineral extractions were made from veins and deposits of tubular shape. Granitic breccias and sectors with abundant potassium feldspar and tourmaline frequently accompany the mineralization of the aforementioned La Fragüita area. $\mathrm{Cu}$ and $\mathrm{Bi}$ were exploited in the eastern edge of the Tocota pluton (Table 2, Dos Amigos mine) (Fig. 6).

The sedimentary unit, pluton host rock, exhibits mineralization in both veins and hydrothermal breccia structures. Cu, As and Bi were exploited in this unit where the zone 4 was heavily mined to obtain As ore (Tables 1 and 3). 
It is probable that after the consolidation of the pluton, ascendant hydrothermal fluids, mixed with meteoric waters, circulated through planes of weakness and both boron-potassic feldspar metasomatism zones and metallic veins in the granites were formed. In both units described, the Cu-As content is high (Figs. 8 and 9, Tables 1 and 2).

This ore deposition model, which was intended to be established for an environment of granitic intrusions, could be reinforced by considering both the partition coefficients and the shape of the intrusions. The coefficients of characteristic elements of the region are: $M n-A s>2$ and $B-C u>10$. These values are indicative of the efficiency of fluid extraction from a pluton (Audetat, 2019). The high degree of erosion affecting the central-southern portion should also be taken into account. In this zone, occurrences of Cu ore are common (Fig. 4, zones 2 and 3) but not for As, where its occurrence is a characteristic of the Tocota district (Zone 4, sedimentary unit, Fig. 4).

The mineralization of the Gondwanan cycle is epigenetic, its distribution pattern is governed by 1) mostly filling of fault structures and joints, 2) fault breccias and magmatic-hydrothermal breccias and 3) igneous reefs with simple metal associations. The geometry of these deposits is lenticular (Tocota, Dos Amigos, El Leoncito), tabular (Los Morteritos structures, Tocota breccia bodies), ore shoots (Rodophis mine) and stockworks (headwaters of the Chorrillo creek) (Table 3).

The stages of mineralization include three groups of paragenetic minerals: silicate phase (late-magmatic and hydrothermal alteration minerals), primary and secondary ore species. In most cases, each group belongs to a defined stage of evolution and, to a lesser extent, up to three stages of deposition (quartz, tourmaline, hematite) have been identified (Tables 4 and 5, Fig. 10).

In this study, several phases of mineral deposition, after the consolidation of the Tocota pluton, have been identified. The oldest fluid phase is interpreted as being of high temperature (higher than $400^{\circ} \mathrm{C}$ ) and the remaining ones between $200{ }^{\circ} \mathrm{C}-350^{\circ} \mathrm{C}$ (Figs. 10 -a and $11 \mathrm{a}-\mathrm{b})$. For this reason, we suggest assigning $a$ widespread mesothermal genesis, both in the copper districts of the Tocota pluton and in the sedimentary unit, for which the related mineralization was injected after other episodes of higher temperature.

In the plutonic unit, there are three geochemical zones of polymetallic type, namely Cu-Bi, with subordinate Mo-As (Zone 1, Dos Amigos mine and Cerro Negro de Tocota), Cu with subordinate Au-Ag-Fe (Zone 2 - La Fragüita, central and southern portions) and $\mathrm{Fe}$ (Zone 3, Leoncito mine) (Fig. 4). Within the sedimentary unit, a geochemical zone characterized by As, with Cu-Au subordinates (Zone 4, Tocota district) was identified and also another with Mn markedly anomalous in the southern portion (Zone 3, Los Morteritos sector). The Au was positively correlated with $\mathrm{Sb}$, As, Mo, and Ag (Fig. 8). Both Cu and these latter elements are anomalous, except for Ag, which is slightly anomalous.

Several zones were verified with hydrothermal alteration mineralogies, amongst them the most prominent are:

Quebrada Larga, with phyllic alteration (quartz-sericite) (Figs. 4 and 12), it includes veins, sedimentary outcrops and andesitic dikes. The right bank of the Tocota stream, with intermediate argillic alteration, around a long breccia dike and in outcrops located south of the Colo-Colo mines. La Fragüita creek, with boron metasomatism through tourmaline, is common in the vicinity of the pluton axis, distributed in the granitic mass and in the sedimentary host rocks (Fig. 4). Potassium alteration has also been identified, by means of potassium feldspar and secondary biotite in the mineralization selvages and wall rocks (Fig. 3, La Fragüita Granites). Leoncito sector, with intermediate argillic and sericitic alterations (Fig. 4), with hematite filling joints, pyrite and fine-grained gold.

A metallotect associated to the Tocota pluton is defined both within the granite and in the sedimentary host rocks (Fig. 4). The identified mineralization may correspond to similar sources, according to isotopic results of $\delta^{34} S$ (3.2 and 3.8 - Wetten, 1998-a), as well as the common vein mineral species (quartz, tourmaline and potassium feldspar, Tables 4 and 5), but other provenances cannot be ruled out

The original set of veins of the Tocota drainage-basin has been abruptly broken by the intrusion of andesite domes in the north of the Tocota pluton (Figs. 3 and 4). These outcrops of Miocene magmatism neither show an anomalous metalliferous content nor a cogenetic link with the cited veins.

\section{Introducción}

Este trabajo intenta definir las características geológico-mineras de la porción sur del Batolito de Colangüil, que se localiza en el borde oriental de la Cordillera Frontal (Fig. 1). Para ello se intentó caracterizar la secuencia de mineralización metalífera neopaleozoi$\mathrm{ca}$, los estilos de mineralización, los rangos de temperatura, las paragénesis minerales y las profundidades de formación de las mineralizaciones.

El sector de estudio se sitúa en el noroeste de la provincia de San Juan (centro-oeste de Argentina), en los departamentos Iglesia y Calingasta, entre las inmediaciones de Tocota por el norte $\left(69^{\circ} 25^{\prime} \mathrm{O} ; 30^{\circ} 35^{\prime} \mathrm{S}\right)$ y el río Castaño, en el sur $\left(69^{\circ} 35^{\prime} \mathrm{O} ; 3^{\circ} 50^{\prime} \mathrm{S}\right)$ (Fig. 2).

La mayoría de los depósitos minerales del borde oriental de la Cordillera Frontal de San Juan, en el ámbito del Batolito de Colangüil, se originaron a partir de procesos relacionados con la actividad ígnea, en un ambiente de arco magmático continental que corresponde al ciclo Gondwánico (Llambías and Sato, 1990; Malvicini and Caminos, 1994).

En relación a los antiguos depósitos explotados se mencionan estudios sobre: arsénico de las minas de 
Tocota (Kittl and Bellio, 1946; Wetten, 1995), W-Sn en las zonas de Arrequintín: quebradas de Mondaca y Pueblo Hundido, respectivamente (Wetten, 1953), Ag en El Salado (Benavídez de Albar Díaz, 2016), Cu-As de la mina Amancay (Llambías and Malvicini, 1966), Bi$\mathrm{Cu}$ de la mina San Francisco de Los Andes (Llambías and Malvicini, 1969) y Au-Ag-Sn de Antecristo (Borelli et al., 1992). Con excepción de las minas de El Salado y Amancay, hospedadas en granito y granodiorita, respectivamente, las restantes se hallan encajadas en la Formación Cerro Agua Negra.

Cabe agregar la existencia de conocidas minas, ubicadas en el departamento Iglesia, cuya secuencia de mineralización se ha asignado al ciclo Andino (Mioceno), entre las cuales se citan los depósitos de $\mathrm{Cu}-\mathrm{Mo}$ (Au-Ag) del pórfido de Chita, de composición tonalítica a diorítica (Fig. 2) (Lara et al., 1993b), Cu-Au en el pórfido dacítico de Vicuñita, distrito El Salado, del Cordón de Colangüil (Fig. 1) (Gemuts et al., 1996).

\section{Metodología}

Las distintas unidades geológicas fueron identificadas en el terreno y se obtuvieron muestras petrográficas para elaborar la cartografía geológica de la unidad plutónica. Se recorrieron las distintas zonas del Plutón Tocota y sus alrededores, a fin de convalidar los resultados geológicos anteriores como así también para ofrecer nueva información, acerca del tipo de mineralización y su abundancia relativa, que pudiera resultar de interés para futuras prospecciones.

La cartografía se ejecutó mediante imágenes Landsat TM. Se emplearon las bandas $7,4,1$ y $7,4,2$ para la discriminación regional de litologías, las bandas $5 / 7$, $5 / 4,3 / 1$ (RGB) para anomalías de color y filtros direccionales para identificación de alineaciones estructurales.

En el laboratorio se determinaron los principales minerales de mena, ganga y de alteración hidrotermal. Entre las técnicas analíticas utilizadas para tratar de establecer las especies mineralógicas se cita el difractómetro de rayos X (GEA - U. Concepción).

La espectrometría de masas se realizó para conocer la procedencia de ciertas especies minerales. Para este fin se realizó la medición de isótopos estables en un espectrómetro de masas VG-ISOTEC SIRA 10 (GEA - U. Concepción), sobre una fase gaseosa de dióxido de azufre generada por reacción química con $\mathrm{Cu}_{2} \mathrm{O}$, desde una muestra monomineral (pulverizada en mortero de ágata) de $100 \mathrm{mg}$ de pirita. Para esta determinación previamente se seleccionaron muestras con sulfuros procedentes de mineral de veta, obtenidas en las campañas de reconocimiento.

Además, con el microscopio de luz polarizada se describieron muestras procedentes del plutón Tocota, de las rocas encajantes y de los cuerpos mineralizados. Esta tarea permitió diferenciar las unidades rocosas y las paragénesis minerales de las distintas zonas del área de estudio.
Con el acoplamiento de una platina de calentamiento-enfriamiento (Linkam TH-600), se determinaron las características de las asociaciones de inclusiones fluidas en cuarzo hidrotermal (ocurrencia, tamaño, forma y fases presentes) y se midieron sus temperaturas de homogenización y enfriamiento. Tales mediciones se repitieron con el método de cycling. Estas actividades específicas se lograron con el importante apoyo del Instituto de Geología Económica Aplicada de la Universidad de Concepción, Chile, y el USGS en Denver (CO). Estas tareas se completaron con la obtención de fotos de microscopía.

La obtención de información geoquímica se inició teniendo en cuenta las investigaciones previas de antiguas minas de la región. Luego se programó un muestreo de tipo litogeoquímico, en el cual quedaron involucrados los siguientes tipos de afloramiento: estructuras mineralizadas - rocas encajantes - sectores de alteración hidrotermal.

En distintas campañas se obtuvieron 45 muestras en la zona 4, que abarca el distrito Tocota (Tabla 1) y otras 3 en zonas ubicadas al noreste y al sur (Tabla 2). Los afloramientos con alteración hidrotermal se muestrearon mediante la extracción de fragmentos de roca sobre un área de aproximadamente $50 \mathrm{~m}^{2}$ y en las estructuras mineralizadas con diseño tabular y/o lenticular se efectuó el muestreo transversalmente al eje mayor de cada una.

La organización de los análisis químicos se basó en aspectos como antecedentes de sustancias explotadas antiguamente, elementos comúnmente asociados a los cationes principales o de interés económico, elementos que comúnmente presentan afinidad granítica como así también otros que habitualmente se incluyen en el conjunto de determinaciones por análisis de ICP-OES.

$\mathrm{Au}$ y $\mathrm{Ag}$ se analizaron (a partir de una muestra de $30 \mathrm{~g}$ ), por gravimetría y absorción atómica (A.A) (Equipo Varian Spectra 55). Los elementos $\mathrm{Cu}, \mathrm{Pb}, \mathrm{Zn}, \mathrm{Mo}$ y As, fueron analizados a partir de disolución mediante ataque ácido y lectura por A.A. (Tabla 1) (SGS Chile Ltda.) y Sb (volátil), Mn, Fe y La, entre otros, por Plasma (ICP 30, 0.500g de muestra, digestión con 3ml 3-1$\left.2 \mathrm{HCl}-\mathrm{HNO}_{3}-\mathrm{H}_{2} \mathrm{O}\right)$. Los límites de detección de estos elementos ocuparon el rango de 0.5 a 50 ppm (Tabla 2) (ACME Analytical Laboratories - Chile).

En los gráficos sólo se ha representado el conjunto de datos de la zona de muestreo de más detalle (Zona 4), sobre distintos grupos identificados como vetas y afloramientos de rocas de caja mineralizadas (Wetten, 1999), a través de la aplicación Rock-Stat, del software Rockware. Este procedimiento además requirió previamente que los datos fueran editados en código ASCII.

Las zonas geoquímicamente anómalas, en el ámbito del plutón Tocota, se delimitaron considerando los resultados positivos que superaron a los promedios y rangos de los diferentes contenidos metálicos (background values) en rocas ígneas y sedimentarias comunes (Hawkes y Webb, 1962). 


\section{Geología}

En la Cordillera Frontal afloran rocas pertenecientes a dos ciclos tectono-estratigráficos diferentes, Gondwánico y Andino, según Ramos (1988 y 1999) (Fig. 1).

1) BASAMENTO PALEOZOICO:

El ciclo Gondwánico está constituido por rocas siliciclásticas originadas esencialmente en un ambiente marino durante el Paleozoico superior (Carbonífero a Pérmico). En el cordón de Olivares, quebrada de Las Leñas, Furque (1962) describió una secuencia carbonífera sobre la base de similitudes con las sedimentitas de la quebrada de Agua Negra (Fig. 1), en el departamento Iglesia. Esta secuencia, que corresponde a la Formación Cerro Agua Negra, en ese sector se apoya discordantemente sobre sedimentitas atribuidas al Devónico (Cardó et al., 2005). En la quebrada de Chita, al oeste del plutón homónimo (Fig. 2), la citada formación está corrida sobre areniscas grises oscuras, con estratificación gradada e intercalaciones de pelitas (Sato, 1989, en Llambías and Sato, 1990), cuya edad aún no ha sido establecida.

En el área de estudio la Formación Cerro Agua Negra (Polanski, 1970) se distribuye comúnmente a modo de roof pendants (Figs. 2 y 3). Mediante estudios paleontológicos esta formación fue asignada al Devónico superior-Carbonífero (Furque, 1962), al Pensilvánico (Carbonífero tardío)-Pérmico (Aparicio, 1969), luego, en el intervalo Pérmico Cisuraliense-Asseliense (González, 1981 y Gutiérrez, 1983) y, posteriormente, su edad fue ubicada en el Carbonífero tardío. Esta última asignación de edad (Busquets et al., $2013 \mathrm{a}$-b) se debe a que en algunos sectores entre esta formación y el Grupo Choiyoi se sitúa la Formación San Ignacio, de edad Carbonífero tardío-Pérmico temprano. La Formación Cerro Agua Negra está compuesta, en forma predominante, por pelitas (limoarcilitas y fangolitas), areniscas medianas a gruesas y escasos conglomerados, cuya coloración varía entre el gris y el verde oscuros. También afloran corneanas de bajo grado de metamorfismo, en el contacto con rocas ígneas del Plutón Tocota. Estas corneanas conservan su textura clástica, de grano muy fino. Ocasionalmente exhiben finas venillas de cuarzo blanco y anfíbol secundario. Además, suelen incluir agregados de escasos milímetros de diámetro, constituidos por anfíboles-biotita-cloritas-cuarzo de mayor tamaño y minerales opacos.

Granitoides de edad Permo-Triásico, del Batolito Compuesto de la Cordillera Frontal (Polanski, 1958), intruyen a las rocas sedimentarias en una amplia región, que abarca los cordones de Olivares, Colangüil, San Guillermo y Santa Rosa (Fig. 1). Posteriormente, Llambías and Sato (1990) emplearon la denominación de Batolito de Colangüil.

Hacia el oeste de los cordones de Colangüil y Olivares, se dispone una unidad volcano-sedimentaria correspondiente al Grupo Choiyoi (Fig. 1), de edad Permo-Triásico, posterior a la fase compresiva San
Rafael, de edad Pérmico inferior (intervalo Sakmariano-Artinskiano, Sato et al., 2015). Estas rocas volcánicas, representadas solamente por sus niveles más antiguos, son ácidas y también intermedias (Sato y Llambías, 1993) y se encuentran en discordancia angular sobre las rocas del basamento Gondwánico. Se relacionan con una importante fase extensional previa a la compresión Andina (Heredia et al., 2002).

En la terminación sur del Batolito de Colangüil se emplaza el pluton Tocota (Llambías and Sato, 1990), que se puede reconocer desde el arroyo Chita, al norte del área estudiada, hasta la margen izquierda del río Castaño, al sur. Se dispone con orientación NNE

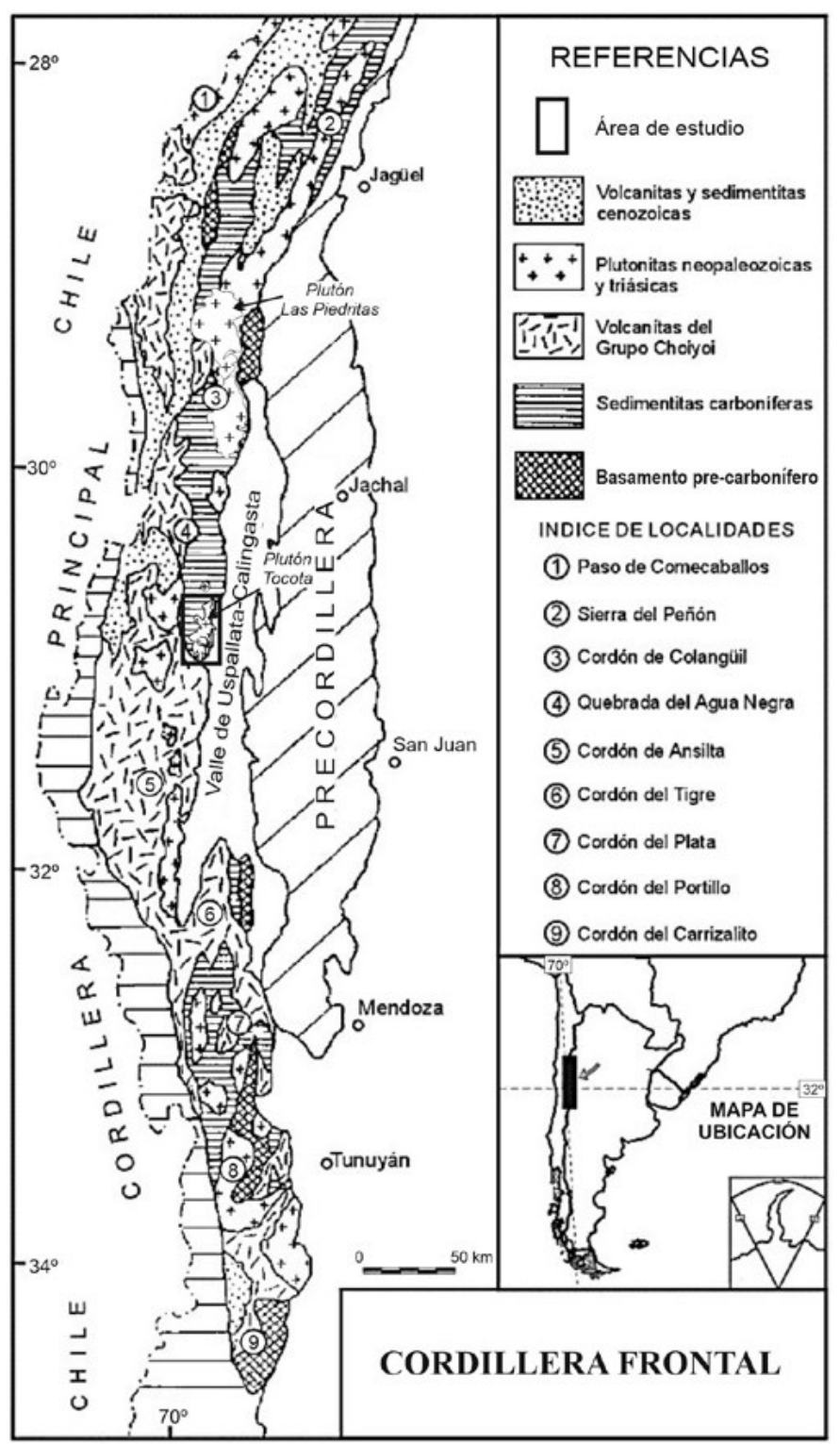

Figura 1. Bosquejo geológico con extensión y límites de la Cordillera Frontal. Adaptado de Ramos (1999) y Sato et al. (2015). Se indica la situación del área estudiada.

Figure 1. Geological sketch, with the extension and limits of the Frontal Cordillera. Adapted from Ramos (1999) and Sato et al. (2015). The location of the study area is indicated. 
- SSO, con una longitud que supera los $25 \mathrm{~km}$ y un ancho que alcanza los $10 \mathrm{~km}$ (Figs. 2 y 3). Los afloramientos se distribuyen mediante una zonación centrípeta irregular (Rodríguez Fernández et al., 1996-b). Corresponden a sucesivos eventos intrusivos que, en orden de edad decreciente, están representados principalmente por tonalitas ocupando las partes externas y facies graníticas posteriores ubicadas en el núcleo del plutón, además de un conjunto de diques mesosilíceos y brechas cuarzo turmalínicas que intruyen tanto a las rocas graníticas como a las sedimentarias paleozoicas. La composición dominante es la de granitoides calcoalcalinos. Según datos geoquímicos, estos cuerpos intrusivos son rocas calcoalcalinas con alto contenido de potasio (Rodríguez Fernández et al., 1996-b). Los contenidos promedio de óxidos mayoritarios, obtenidos en granodiorita, son $66 \% \mathrm{SiO}_{2}$, $15.85 \% \mathrm{Al}_{2} \mathrm{O}_{3}, 1.40 \% \mathrm{Fe}_{2} \mathrm{O}_{3}, 3.20 \% \mathrm{FeO}, \mathrm{FeOt} / \mathrm{FeOt}+\mathrm{M}^{\prime \prime}-$ $\mathrm{gO}=0.69,2.08 \% \mathrm{MgO}, 3.68 \% \mathrm{CaO}, 2.80 \% \mathrm{Na}_{2} \mathrm{O}, 2.90 \%$ $\mathrm{K}_{2} \mathrm{O}$ y $0.14 \% \mathrm{P}_{2} \mathrm{O}_{5}$ (Castro, 1991 y Sato and Llambías, 1993). Las texturas más frecuentes de estas facies

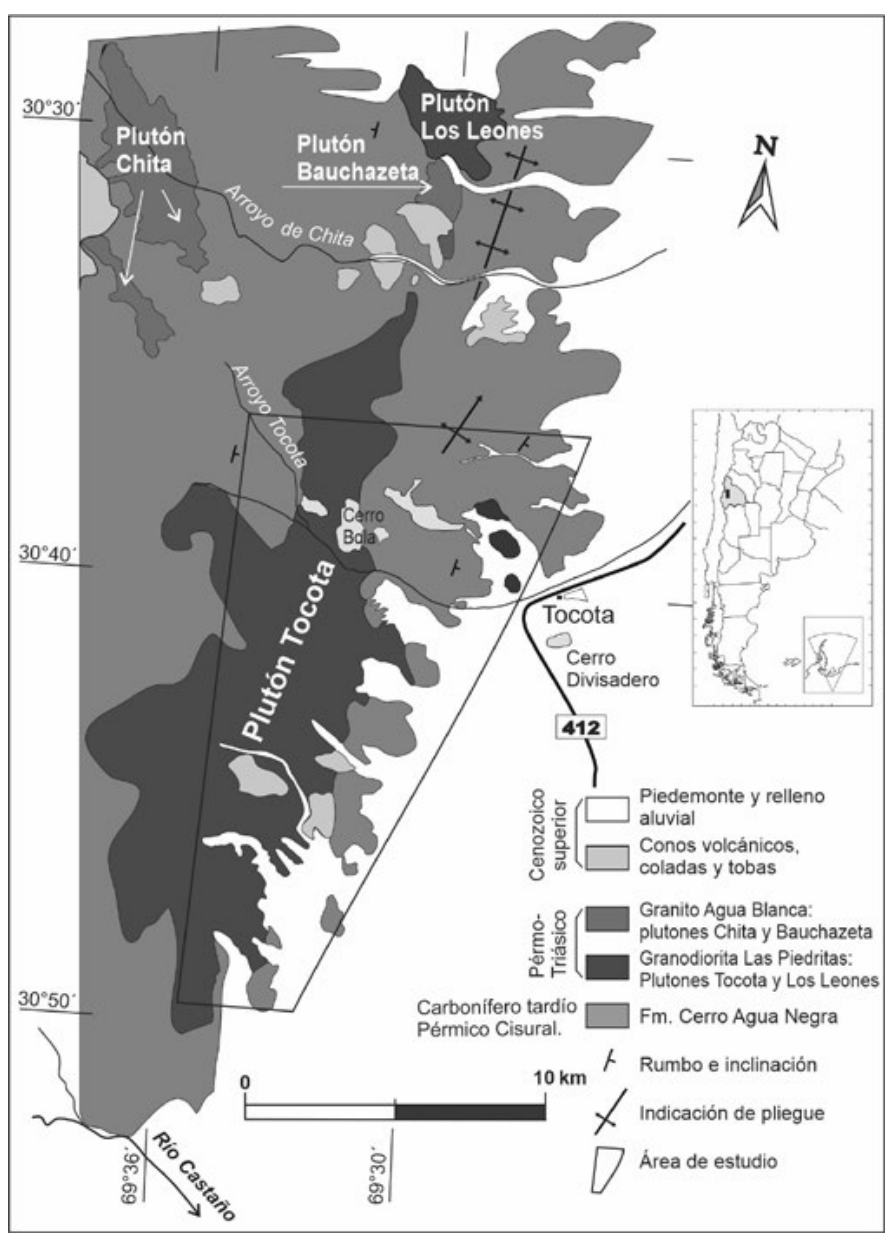

Figura 2. Mapa geológico simplificado de la porción sur del Batolito de Colangüil. Oeste de la provincia de San Juan.

Figure 2. Simplified geological map of the southern portion of the Colangüil Batholith. West of the province of San Juan. son las equigranulares hipidiomórficas, a veces intersertales, o heterogranulares xenomórficas de grano grueso a medio con tendencia porfídica. Además, hay desarrollo de sectores pegmatoides en el granito de la zona de La Fragüita (Fig. 3). Están compuestos de plagioclasa $\left(A n_{26-45}\right)$, hornblenda, biotita, agregados de tremolita-actinolita y escaso clinopiroxeno. Excepto en las granodioritas, y en los granitos (Wetten, 1998b), el cuarzo y el feldespato alcalino son escasos, de naturaleza intersticial o se producen como intercrecimientos gráficos (Heredia et al., 2002). La titanita es el accesorio más abundante (Llambías and Malvicini, 1966). Además, la magnetita titanífera y el apatito son relativamente abundantes en diques andesíticos y en las vecindades de zonas con turmalina, respectivamente.

Algunas unidades graníticas muestran enriquecimiento en boro, con el resultado de importantes cristalizaciones de turmalina a modo de agregados fibrosos con disposición radial de más de $5 \mathrm{~cm}$ de diámetro, relleno de diaclasas dentro de los granitoides, reemplazos pervasivos, rellenos de vetas y formación de chimeneas de brecha. Algunas de estas zonas con turmalinización contienen mineralizaciones de Bi-AsCu (Llambías and Malvicini; 1966; 1969; Llambías et al.; 1987).

Los diques son menos frecuentes que en otros sectores del batolito de Colangüil, en su mayoría son de tipo dilatacional. Por lo expuesto se infiere que los esfuerzos tensionales fueron contemporáneos con la actividad magmática (Llambías and Sato, 1990). Son alargados, paralelos al eje del plutón y en general con un metro o menos de espesor. Se caracterizan por una composición andesítica, con fenocristales de plagioclasas y minerales accesorios de biotita y turmalina. La pasta, fanerítica, está constituida por plagioclasas y biotita, con escasos minerales de cobre diseminados (Centro-sur del plutón) y diseminación de pirita (Norte del plutón). En la zona de La Fragüita contienen inclusiones ovoidales de granito de hasta 5 $\mathrm{cm}$ de diámetro.

El nivel de emplazamiento, de la porción sur del batolito de Colangüil, es muy superficial, habiendo determinado Sato (1989) y Llambías and Sato (1990) una profundidad de $1.3 \mathrm{~km}$ para el plutón de Chita, en proximidades del plutón Tocota (Figs. 1 y 2).

El plutónTocota es pos-tectónico, respecto de la fase orogénica San Rafael y tuvo lugar durante el Pérmico Cisuraliense (Llambías and Sato, 1990). Por lo tanto, se lo incluye dentro del ciclo magmático Gondwánico (Carbonífero y Pérmico-Triásico) (Malvicini and Caminos, 1994). El plutón Tocota forma parte de la unidad batolítica Las Piedritas (fase mineralógica principal: biotita-anfíbol-opacos), la más antigua del Batolito de Colangüil. En otras zonas de este batolito, próximas y similares al plutón Tocota (Las Piedritas, Fig. 1), se obtuvieron edades de 264 y 269-267 Ma por el método de Rb-Sr (Llambías and Sato, 1990) y posteriormente edades U-Pb de $278.8 \pm 3.4 \mathrm{Ma}$ y $252.5 \pm 1.9 \mathrm{Ma}$ (Sato 
et al., 2015) fueron establecidas para rocas plutónicas del batolito de Colangüil y unidades volcánicas del Grupo Choiyoi.

\section{2) PRODUCTOS EFUSIVOS CENOZOICOS (CICLO} ANDINO):

Este ciclo presenta una importante laguna estratigráfica que abarca la mayor parte del Mesozoico; se compone de rocas sedimentarias y volcano-sedimentarias, de marcado origen continental y edad cenozoica predominante. Estas rocas yacen a modo de domos y diques; intruyen a las rocas del Plutón Tocota y de la formación Cerro Agua Negra y se disponen en cotas que comúnmente superan los $3000 \mathrm{~m}$. Se pueden diferenciar las siguientes unidades:

Grupo Melchor (Rodríguez Fernández et al., 1996-a). En las quebradas de Tocota y de Los Morteritos se destacan bancos de tobas y aglomerados tobáceos, discordantes sobre las unidades paleozoicas graníticas y sedimentarias (Fig. 3). Los afloramientos son más extensos en las nacientes de Los Morteritos. Los aglomerados tobáceos presentan una textura fragmentaria, con cristales de plagioclasas, cuarzo y biotita y litoclastos. Estos últimos exhiben abundante calcita a modo de parches. Poseen alteración a materiales arcillosos como así también a clorita.

Grupo Olivares (Rodríguez Fernández et al., 1996-a). Se asignan a este grupo los pórfidos andesíticos a dacíticos que afloran en el arroyo de Chita, al norte del área de estudio (Sato, 1989, Bastías, 1991) (Fig. 2), con edades tan jóvenes como 4.6 Ma (Poma et al., 2017). También afloran coladas de basaltos y basandesitas, distribuidos en el Cordón del Olivares y al sur de la quebrada del Agua Negra (Fig. 1). Los afloramientos del Cerro Divisadero (Figs. 2, 3 y 4) se incluyen tentativamente en el mismo grupo, al considerar una datación K-Ar, sobre feldespato potásico, de $18.3 \pm 2.5 \mathrm{Ma}$ (Leveratto, 1976). Estas rocas están constituidas por un pórfido dacítico gris claro, macizo, con textura fluidal, pasta fanerítica y xenolitos de granodiorita.

Formación Lomas Claras (Wetten, 2005). Esta formación está compuesta por un grupo de afloramientos subvolcánicos relacionados genética y estructuralmente entre sí, cuyos principales exponentes son los cerros Bola y de los Pozos, como así también algunos afloramientos situados al norte de este último, en la quebrada de Los Frijoles (Fig. 3). Esta unidad se destaca en el relieve y se extiende sobre un área de aproximadamente $25 \mathrm{~km}^{2}$. Se trata de una unidad litoestratigráfica de composición andesítica, formada por domos y coladas sin alterar y con abundante anfíbol y biotita. Esta unidad comprende sólo los cuerpos magmáticos mencionados $\mathrm{y}$, dadas sus características, se asigna al Grupo Olivares. Una datación radiométrica efectuada por el método K-Ar sobre anfíbol, dio una edad de $8.80 \pm 0.3 \mathrm{Ma}$ (Wetten, 1999).

\section{3) ASPECTOS ESTRUCTURALES}

En el período Carbonífero-Pérmico temprano, la Cordillera Frontal tuvo una posición de retroarco (Ramos, 1988). En este marco tectónico, la evolución se- dimentaria más probable habría sido la propagación de un sistema deltaico desde la Precordillera y Sierras Pampeanas hacia la Cordillera Frontal, donde inicialmente habrían encontrado condiciones marinas más abiertas. Durante el depósito de la sucesión sinorogénica del Pérmico, un cambio dramático del área fuente de sedimentos tuvo lugar en la Cordillera Frontal. En ese momento, el levantamiento de un arco volcánico y un basamento Famatiniano se evidencia por la presencia de rodados volcánicos y sedimentarios en los conglomerados con proveniencia del oeste. El marco geotectónico más probable de la Cordillera Frontal, en esa época, es una cuenca de retroarco-antepaís. Este evento puede relacionarse a la orogenia Gondwánica, con el mismo sentido de propagación (Heredia et al., 2002).

Todas estas rocas fueron fuertemente deformadas por una tectónica epidérmica (thin-skinned) durante

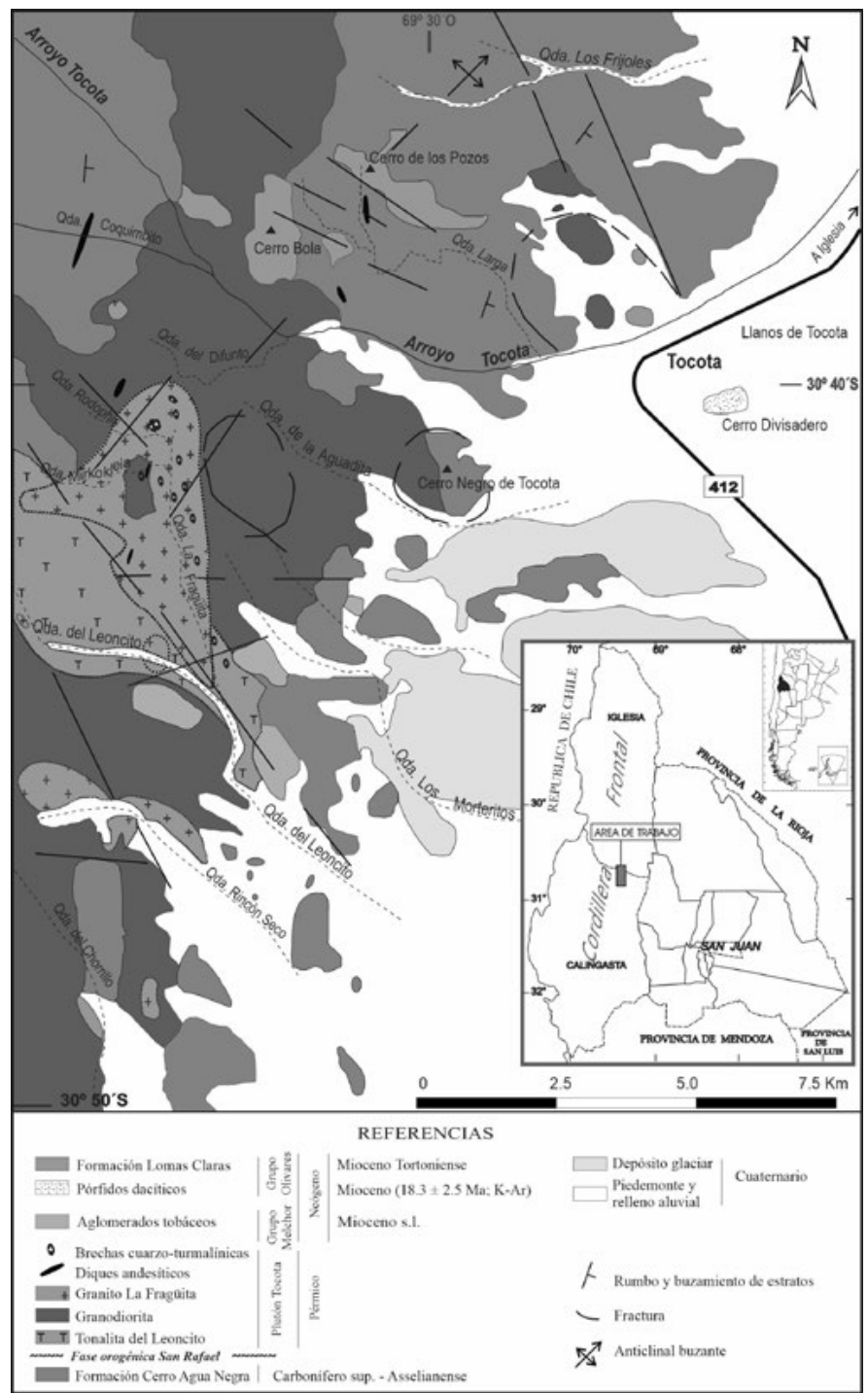

Figura 3. Mapa geológico del área de estudio.

Figure 3. Geological map of the study area. 
el ciclo orogénico Gondwánico. Las estructuras más importantes son las escamas de cabalgamiento y pliegues relacionados con dirección de transporte tectónico hacia el este, produciendo un acortamiento muy importante (60-70\%) (Heredia et al., 2002). La compresión originada por la fase orogénica San Rafael, durante el Pérmico Cisuraliense, produjo la elevación tectónica de la región, lo cual condujo al desarrollo de una superficie de erosión sobre la cual se depositaron las primeras erupciones volcánicas del Grupo Choiyoi, desarrolladas en una etapa extensional (Heredia et al., 2002) y contemporáneas con el comienzo de la intrusión del batolito de Colangüil (Llambías and Sato, 1990). Los granitoides del Paleozoico superior-Triásico evolucionaron desde un magmatismo calcoalcalino, típico de un ambiente orogénico vinculado con subducción, a otro alcalino y peralcalino anorogénico. Éstos intruyeron en un período extensional (colapso orogénico), desarrollado luego de la unión de terrenos exóticos del margen de Gondwana durante la orogenia Gondwánica (Heredia et al., 2002).

El contacto entre la Formación Cerro Agua Negra y los plutones del batolito de Colangüil tiene una dirección aproximadamente norte-sur (Fig. 1). Este sector de la Cordillera se caracteriza por una tectónica de bloques afectados por fallas de alto ángulo. Las principales fracturas regionales tienen rumbos NNE y NO (Fig. 3). La vergencia de las estructuras Gondwánicas y Andinas es hacia el E, si bien el tipo y morfología de éstas varía al caracterizarse por una intensidad de deformación diferente. En el caso del ciclo Andino, de carácter compresional, éste presenta en la región considerada un escaso acortamiento $(10 \%)$ y un predominio de la tectónica que involucra al basamento, con escasas estructuras plegadas relacionadas y, además, produce la inversión de las estructuras extensionales previas (Rodríguez Fernández et al., 1996-a, 2002). También se desarrolla una apretada red de fracturas de distinto carácter, resultado de las diferentes fases de deformación Andina, ocurridas en condiciones frágiles (Baraldo et al., 2002) (Fig. 3).

Las rocas de la Formación Cerro Agua Negra poseen un rumbo variable entre NNE y NS y en la zona de estudio inclinan hacia el E - ESE. Esta secuencia se dispone mediante pliegues NE-SO y N-S con una longitud de onda que supera los 500 metros (Fig. 3). El emplazamiento de las rocas graníticas, en la parte sur del batolito de Colangüil estudiada, provocó una ligera deformación en la Formación Cerro Agua Negra y algunas estructuras circulares de intrusión (NE del área, mina Dos Amigos) como así también pliegues con su eje inclinado. Las estructuras circulares se distinguen principalmente en el frente de montaña, en las proximidades de la localidad de Tocota (Fig. 3). Se han interpretado como bordes de intrusión de stocks granodioríticos subyacentes, reflejarían tanto rasgos de superficie como de carácter más profundos (Wetten, 1997). Los intrusivos de edad Neógeno (Ciclo Andino) intruyen las rocas citadas del basamento Paleozoico (Figs. 2 y 3 ).

\section{Distribución de las zonas geoquímicas y asociaciones mineralógicas identificadas}

El ambiente metalogenético del Plutón Tocota consiste en dos unidades principales: granitoides y roca encajante sedimentaria (Formación Cerro Agua Negra). Éstas se caracterizan por exhibir una distribución geoquímica bien evidenciada de los metales $\mathrm{Cu}, \mathrm{Au}$ y $\mathrm{As}$ y en mayor o menor medida, de Fe y Bi. A partir de la distribución de los elementos químicos analizados se propone la presencia de cuatro zonas geoquímicas levemente diferentes, en su mayoría con antiguas minas, cada una con una determinada asociación metalífera. Estas zonas se denominan 1, 2, 3 y 4 y se muestran en el mapa de la figura 4.

Zona 1: dominada por el cobre, al que se asocian $\mathrm{Bi}$, Mo y As. El Cu está presente con contenidos elevados, entre cientos y miles de ppm (Tablas 2 y 3). Esta

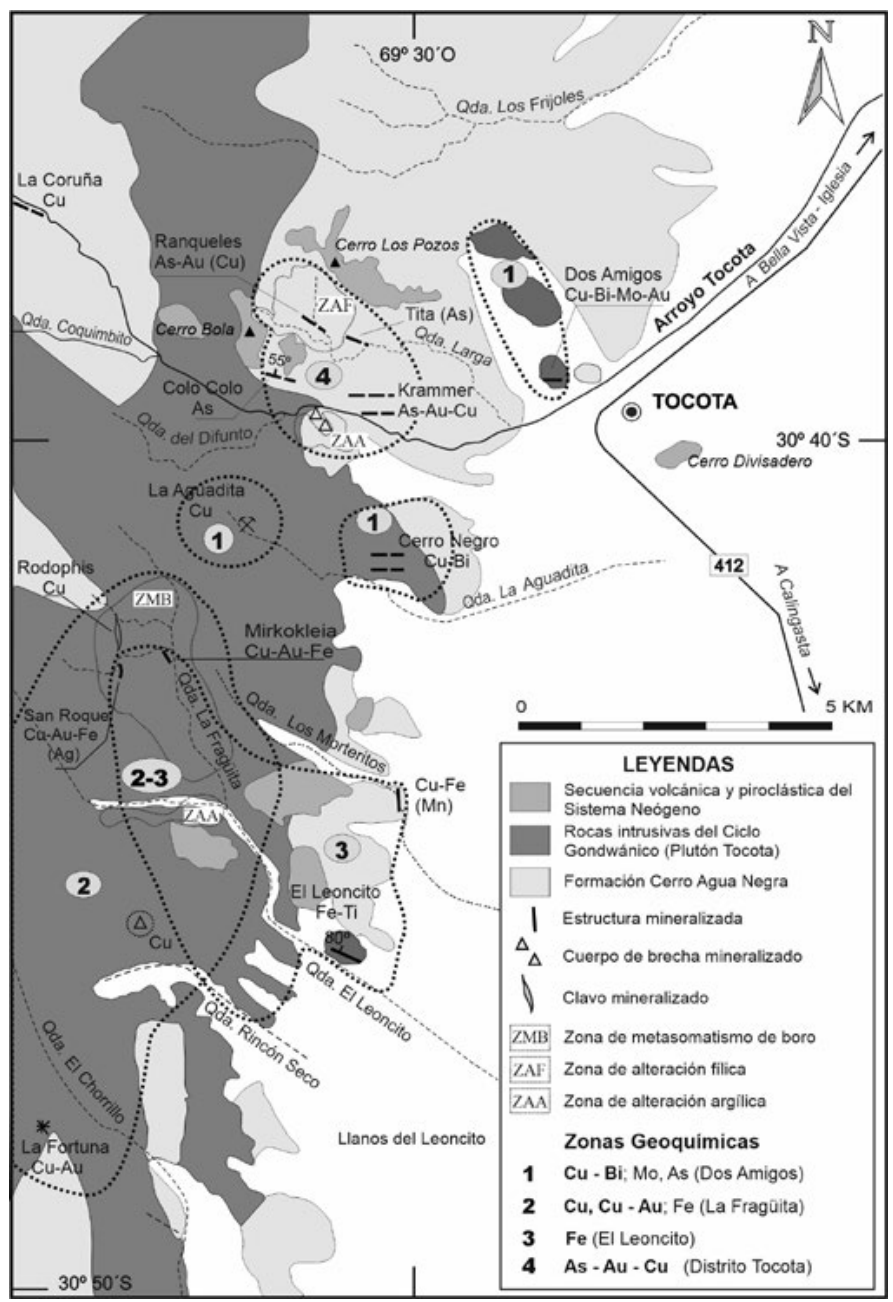

Figura 4. Distribución de depósitos minerales y zonas geoquímicas relacionadas con el Ciclo Gondwánico y referidas al plutón Tocota y su roca encajante.

Figure 4. Distribution of mineral deposits and geochemical zones related to the Gondwanan Cycle and referred to the Tocota pluton and its host rock. 
asociación se localiza con concentraciones mayores hacia el borde oriental del plutón Tocota. Las abreviaturas minerales (Tabla 3) se emplearon según Whitney and Evans (2010).

Las mineralizaciones (Dos Amigos, Cerro Negro de Tocota) se distribuyen en juegos de vetas paralelas, alojadas en estructuras de falla E-O, verticales (Fig. 4, Tabla 3). La roca encajante es una granodiorita milonitizada y presenta enclaves de tonalita. Las vetas están conformadas por filones de cuarzo blanco, con textura bandeada (Fig. 5). Como minerales de mena se identificaron calcopirita como primario y covelina, calcosina, malaquita, azurita y jarosita como secundarios, en ganga de cuarzo, turmalina y escasa calcita. Los muros de las vetas comúnmente están constituidos por un producto de meteorización arcilloso de la caja. Además de los citados juegos de vetas, se presentan conjuntos de vetillas $\mathrm{E}-\mathrm{O}$ de cuarzo macizo, de $1 \mathrm{~cm}$ de potencia y con bordes de turmalina.

Los tenores químicos obtenidos a partir de una muestra sobre veta (Tabla 2) arrojaron valores anómalos en $\mathrm{Au}, \mathrm{Ag}, \mathrm{Cu}, \mathrm{Bi}, \mathrm{Mo}$ y $\mathrm{As}$, entre los que se destacan $\mathrm{Au}$ con casi $0.5 \mathrm{ppm}, \mathrm{Cu}$ con el $1 \%$, Bi con 158 ppm y Mo con 123 ppm.

Zona 2 - La Fragüita: se trata de vetas o filones en la unidad granítica, próximas al eje del plutón (Fig. 4). Poseen una asociación metalífera de $\mathrm{Cu}, \mathrm{Fe}, \mathrm{Bi}, \mathrm{Au}$ y otra menos concentrada de Ag, Mo, As, Fe y U (Tabla 3 y Fig. 4), con poca diseminación en las rocas encajantes, como así también en brechas turmalínicas cercanas a los depósitos (Pelichotti and Rojo, 1979; Mas and Olivares, 1997. Tablas 2 y 3). Los sectores con anomalías están representados, de norte a sur, por las minas Rodophis, San Roque y Mirkokleia, sector Rincón Seco y mina La Fortuna.

El mayor número de explotaciones cupríferas se haIla en la facies monzogranítica. En minas de la unidad sedimentaria, el cobre fue obtenido como subproducto. En la mina Rodophis (Figs. 4 y 6), la asociación mineralógica hipogénica está dada por pirita, calcopirita, magnetita, ilmenita y oro. Entre los minerales secundarios se reconocieron covelina, calcosina, tenorita, crisocola, rutilo, hematites, jarosita y limonitas no determinadas. La ganga es de cuarzo, calcita y yeso. En la mina San Roque los minerales primarios consisten en calcopirita, casiterita, scheelita, oro de grano fino, ilmenita y rutilo; los secundarios en hematites, malaquita y crisocola escasa. La ganga es de cuarzo, turmalina y moscovita. En la mina Mirkokleia, la mineralización está constituida por pirita, calcopirita, bismutinita, oro de grano fino, casiterita escasa y rutilo como minerales primarios, con hematites, cobre nativo, cuprita, covelina, digenita, limonitas y posible tenorita como secundarios (Tabla 4). La ganga la conforman cuarzo, turmalina, titanita, allanita con contenidos en lantano y cerio de $7.71 \%$ LaO y $13.61 \%$ $\mathrm{CeO}$, y escasa baritina. Análisis químicos efectuados arrojaron leyes bajas en general, con una máxima del $2.4 \%$ de $\mathrm{Cu}$ y hasta 250 ppm de Bi (Tabla 3).
En la quebrada La Fragüita se distribuye una cantidad importante de cuerpos de brecha con cuarzo y turmalina, tienen geometría irregular y tamaños que superan $1 \mathrm{~m} 3$. Es común que contengan una discreta diseminación de sulfuros, minerales secundarios de cobre y también oro de grano fino (Figs. 3 y 7-a).

La mina La Fortuna es la más austral del área mapeada, consiste de estructuras radiales cupro-auríferas hospedadas en granodiorita. Se han registrado contenidos entre 3 y $8 \mathrm{~g} / \mathrm{t}$ de Au y hasta $12 \%$ de $\mathrm{Cu}$ (Tabla 3, Fig. 4).

Zona 3: situada hacia el sur de la región (Fig. 4) y de extensión reducida.

En las quebradas de Los Morteritos y El Leoncito y en las minas Mirkokleia y San Roque el hierro es el elemento más importante. Los resultados del muestreo sobre una estructura mineralizada en Los Morteritos, alojada en la unidad sedimentaria, mostraron anomalías geoquímicas positivas en varios elementos: $\mathrm{Cu}$ - As - Au - Ag - Mn - Fe y, en menor grado, Re y La (Tabla 2, Fig. 4). Algo más al sur y en la desembocadura de la quebrada El Leoncito, se registraron anomalías principalmente en $\mathrm{Fe}$ y $\mathrm{Bi}: 2.66 \%$ y 3 ppm, respectivamente (Fig. 4 y Tabla 2 ).

En la margen izquierda y desembocadura de la quebrada del Leoncito se encuentra una estructura mineralizada con orientación $\mathrm{N} 72^{\circ} \mathrm{O} ; 80^{\circ} \mathrm{N}$ (Fig. 4), encajada en roca granítica alterada a caolín $\mathrm{y}$, además, objeto de explotación por mineral de hierro en el pasado. La mineralización reconocida consiste principalmente de magnetita y hematites, en ganga de cuarzo y turmalina. Los minerales de hierro citados han invadido la roca de caja mediante relleno de fisuras de $1 \mathrm{~cm}$ de espesor. Llambías and Malvicini (1969) mencionan para este sector, además de los minerales de mena citados, magnetita titanífera, ilmenita, rutilo y pequeñas cantidades de pirita.

Zona 4 - distrito Tocota: esta zona estuvo sometida a una fuerte extracción mineral, principalmente en vetas alojadas en la Formación Cerro Agua Negra (Fig. 4). Presenta una distribución geoquímica relativamente homogénea, con algunas variaciones, el arsénico es el elemento más abundante y también el de distribución más uniforme (Tablas 1, 3 y Fig. 4). Las vetas muestran valores que oscilan entre 2-8\% de As y que ocasionalmente superan el $23 \%$. Existe además una buena correlación positiva entre Au-As (Fig. 8). En las rocas encajantes sedimentarias, y en diques andesíticos, los valores de fondo oscilan entre 35 y más de 600 ppm de As, con algunos valores erráticos que superan las 10000 ppm. La distribución del contenido de As en las rocas sedimentarias tiene un valor medio de 1141.60 ppm (Fig. 9). De forma subordinada, se distribuyen $\mathrm{Cu}-\mathrm{Fe}-\mathrm{Ag}-\mathrm{Sb}-\mathrm{Mo}-\mathrm{Bi}-\mathrm{Re}$ y trazas de lantano (Tablas 1 y 2 ).

El cobre ha sido identificado en todo el ámbito de esta zona 4, ya sea por diseminación o vetillas, con valores algo bajos, aproximadamente entre 10 y 500 ppm y excepcionalmente más de 2400 ppm (Tabla 1). 


\begin{tabular}{|c|c|c|c|c|c|c|c|c|c|c|}
\hline \multirow{2}{*}{ MUESTRA } & $\mathrm{Au}$ & $\mathbf{A g}$ & $\mathrm{Cu}$ & $\mathbf{P b}$ & $\mathrm{Zn}$ & Mo & As & Sb & \multirow{2}{*}{ IDENTIFICACIÓN } & \multirow{2}{*}{ UBICACIÓN } \\
\hline & $\mathrm{g} / \mathrm{t}$ & \multicolumn{7}{|c|}{$\mathrm{ppm}$} & & \\
\hline AW 01 & 0.06 & 0.9 & 131 & 29 & 7 & 7 & - & - & \multirow{2}{*}{$\begin{array}{c}\text { Dique de Brecha } \\
\text { Arenisca }\end{array}$} & \multirow{2}{*}{ Minas Colo Colo } \\
\hline AW 02 & 0.05 & 1.7 & 450 & 12 & 19 & 1 & 126 & 23 & & \\
\hline AW 03 & 0.12 & 6.4 & 2493 & 41 & 49 & \multirow[t]{2}{*}{1} & 315 & \multirow[t]{2}{*}{111} & Brecha & \multirow{2}{*}{ Minas Krammer } \\
\hline AW 04 & 0.23 & 1.5 & 55 & 14 & 7 & & 356 & & Brecha & \\
\hline AW 05 & $<0.02$ & $<0.5$ & 6 & 14 & 6 & & 60 & & \multirow{2}{*}{$\begin{array}{c}\text { Estr. silicificada } \\
\text { Arenisca }\end{array}$} & \multirow{15}{*}{ Quebrada Larga } \\
\hline AW 06 & 0.20 & 0.5 & 35 & 15 & 10 & 16 & - & - & & \\
\hline AW 07 & $<0.02$ & & 33 & & & & 256 & & Arenisca & \\
\hline AW 08 & $<0.02$ & & 6 & & & & 45 & & Arenisca & \\
\hline AW 09 & $<0.02$ & $<0.5$ & 23 & 8 & 5 & & 101 & & Arenisca & \\
\hline AW 10 & 0.83 & 1.0 & 72 & 15 & 4 & & 17480 & & Mena & \\
\hline AW 11 & 0.05 & & 15 & & & & 145 & & Arenisca & \\
\hline AW 12 & 0.07 & & 25 & & & & 92 & & Arenisca & \\
\hline AW 13 & $<0.02$ & \multirow[t]{2}{*}{0.6} & 17 & 19 & \multirow[t]{2}{*}{29} & & 62 & & \multirow{7}{*}{$\begin{array}{c}\text { Arenisca } \\
\text { Brecha } \\
\text { Arenisca } \\
\text { Arenisca } \\
\text { Arenisca } \\
\text { Pórfido } \\
\text { Mena }\end{array}$} & \\
\hline AW 14 & 0.05 & & 59 & & & & 900 & & & \\
\hline AW 15 & $<0.02$ & \multirow[t]{3}{*}{0.5} & 33 & 14 & \multirow[t]{3}{*}{14} & & 122 & & & \\
\hline AW 16 & 0.15 & & 11 & & & & 1160 & & & \\
\hline AW 17 & 0.02 & & 23 & & & & 410 & & & \\
\hline AW 18 & $<0.02$ & \multirow[t]{2}{*}{1.5} & 371 & 22 & \multirow[t]{2}{*}{46} & & 88 & & & \\
\hline AW 19 & 5.01 & & 389 & & & & 84000 & & & \\
\hline AW 20 & $<0.02$ & $<0.5$ & 21 & 9 & 32 & & 259 & \multirow{3}{*}{9} & \multirow{4}{*}{$\begin{array}{c}\text { Pórfido } \\
\text { Arenisca } \\
\text { Estr. mineralizada } \\
\text { Arenisca }\end{array}$} & \\
\hline AW 21 & 0.03 & 0.3 & 168 & 7 & 27 & 7 & 144 & & & \\
\hline AW 22 & $<0.02$ & & 15 & & & & 172 & & & \\
\hline AW 23 & 0.07 & $<0.5$ & 47 & 32 & 17 & 5 & - & - & & \\
\hline AW 24 & 0.34 & 1.2 & 540 & 20 & 38 & 3 & 18947 & 125 & Arenisca & \\
\hline AW 25 & 2.30 & 0.5 & 108 & 25 & 6.5 & 6 & 97500 & 137 & Mena & \\
\hline AW 26 & $<0.02$ & & 36 & & & & 669 & & Arenisca & \\
\hline AW 27 & $<0.02$ & 1.2 & 182 & 9 & 8 & & 302 & & Estr. mineralizada & \\
\hline AW 28 & $<0.02$ & 0.6 & 46 & 11 & 57 & & 485 & & Brecha & Minas del Grupo \\
\hline AW 29 & 0.80 & 1.5 & 179 & 41 & 9 & & 44950 & & Mena & Krammer \\
\hline AW 30 & $<0.02$ & & 14 & & & & 232000 & & Estr. mineralizada & \\
\hline AW 31 & $<0.02$ & 0.8 & 56 & 20 & 46 & & 67 & & Arenisca & \\
\hline AW 32 & 0.03 & & 37 & & & & 279 & & Mena & \\
\hline AW 33 & $<0.02$ & 0.6 & 137 & 14 & 11 & & 432 & & Arenisca & \\
\hline AW 34 & $<0.02$ & & 49 & & & & 442 & & Arenisca & \\
\hline AW 35 & $<0.02$ & & 24 & & & & 126 & & Arenisca & \\
\hline AW 36 & $<0.02$ & & 12 & & & & 175 & & Arenisca & \\
\hline AW 37 & 0.04 & & 26 & & & & 207 & & Pórfido & \\
\hline AW 38 & 0.33 & & 65 & & & & 14500 & & & \\
\hline AW 39 & 0.03 & & 425 & & & & 840 & & $\stackrel{\pi}{\simeq}$ & \\
\hline AW 40 & $<0.02$ & 0.5 & 158 & 10 & 290 & & 432 & & قِ & Margen derecha del \\
\hline AW 41 & 0.06 & 0.3 & 210 & 6 & 206 & 10 & 1062 & 3 & $\frac{0}{0}$ & arroyo Tocota (Próximo \\
\hline AW 42 & 0.01 & 0.8 & 255 & 18 & 191 & - & 708 & - & $\stackrel{0}{=}$ & a minas Grupo \\
\hline AW 43 & 0.04 & 0.3 & 501 & 9 & 101 & 4 & 610 & 3 & $\frac{\sigma}{0}$ & Krammer) \\
\hline AW 44 & 0.03 & 0.3 & 141 & 5 & 4 & 2 & 254 & 3 & & \\
\hline 457 & 0.005 & 0.5 & 24 & 19 & 15 & 1 & 30 & 4 & Arenisca brechoide & Quebrada Larga \\
\hline
\end{tabular}

Tabla 1. Resultados químicos por vía húmeda y ensayo a fuego correspondientes al distrito Tocota (Zona geoquímica 4). En la Tabla se incluyen muestras del dique de brecha que se extiende sobre la margen derecha del arroyo Tocota y próximo a las minas Krammer.

Table 1. Chemical results by wet process and fire assay of the Tocota district (Geochemical zone 4). The Table includes samples of the breccia dike that extends on the right bank of the Tocota stream and next to the Krammer mines. 


\begin{tabular}{|c|c|c|c|c|c|c|c|c|c|c|c|c|c|c|c|c|c|}
\hline \multirow{2}{*}{ MUESTRA } & \multirow{2}{*}{ IDENTIFICACIÓN } & $\mathrm{Au}$ * & Ag & $\mathrm{Cu}$ & $\mathbf{P b}$ & Zn & Mo & $\mathrm{Hg}$ & Sb & $\mathbf{N i}$ & Co & Mn & \multirow{2}{*}{$\begin{array}{c}\mathrm{Fe} \\
\%\end{array}$} & As & $\mathbf{U}$ & Th & $\mathrm{Sr}$ \\
\hline & & \multicolumn{11}{|c|}{ ppm } & & \multicolumn{4}{|c|}{ ppm } \\
\hline AW 02 & Arenisca (Colo Colo Tocota) & $<0.02$ & 1.7 & 450 & 12 & 19 & 1 & & 23 & 5 & 2 & 102 & 0.98 & 126 & 0 & 2 & 11 \\
\hline AW 03 & Brecha (Minas Krammer) & 0.12 & 6.4 & 2493 & 41 & 49 & 1 & & 111 & 8 & 3 & 139 & 1.58 & 315 & 0 & 4 & 17 \\
\hline AW 21 & Arenisca (Minas Krammer) & 0.03 & 0.3 & 168 & 7 & 27 & 7 & & 9 & 1 & 4 & 133 & 1.54 & 144 & 0 & 4 & 12 \\
\hline AW 24 & Arenisca (Minas Krammer) & 0.34 & 1.2 & 540 & 20 & 38 & 3 & & 125 & 9 & 15 & 159 & 3.96 & 18947 & 0 & 7 & 49 \\
\hline AW 25 & Mena (Minas Krammer) & 2.13 & 0.5 & 109 & 24 & 6 & 6 & & 137 & 81 & 480 & 449 & 7.55 & 97500 & 8 & 7 & 15 \\
\hline AW 41 & $\begin{array}{l}\text { Dique de brecha (Margen derecha arroyo } \\
\text { Tocota) }\end{array}$ & 0.06 & 0.3 & 210 & 6 & 206 & 10 & & 3 & 64 & 76 & 719 & 8.47 & 1062 & 8 & 5 & 17 \\
\hline AW 43 & $\begin{array}{l}\text { Dique de brecha (Margen derecha arroyo } \\
\text { Tocota) }\end{array}$ & 0.04 & 0.3 & 501 & 9 & 101 & 4 & & 3 & 25 & 24 & 221 & 6.66 & 610 & 8 & 5 & 23 \\
\hline AW 44 & $\begin{array}{l}\text { Dique de brecha (Margen derecha arroyo } \\
\text { Tocota) }\end{array}$ & 0.03 & 0.3 & 141 & 5 & 4 & 2 & & 3 & 5 & 2 & 81 & 1.89 & 254 & 8 & 4 & 31 \\
\hline LM 1 & Veta (Los Morteritos) & 0.15 & 9.1 & 437 & 17 & 80 & 13 & & 25 & 25 & 32 & 2367 & 5.81 & 1241 & 8 & 4 & 115 \\
\hline DAM & Veta (Dos Amigos) & 0.41 & 25.6 & 9736 & 286 & 86 & 123 & & 8 & 12 & 20 & 117 & 2.80 & 285 & 10 & 2 & 14 \\
\hline EL 7 & Tonalita (EI Leoncito) & $<0.02$ & 0.3 & 90 & 20 & 7 & 6 & & 3 & 6 & 1 & 97 & 2.66 & 20 & 8 & 15 & 19 \\
\hline 457 & Arenisca brechoide (Quebrada Larga) & $<0.02$ & 0.5 & 24 & 19 & 15 & $<2$ & 0.023 & 4 & & & & & 30 & & & \\
\hline
\end{tabular}

\begin{tabular}{|c|c|c|c|c|c|c|c|c|c|c|c|c|c|c|c|c|c|}
\hline & & Cd & $\mathrm{Ba}$ & $\mathrm{Bi}$ & V & $\mathbf{w}$ & $\mathbf{P}$ & La & $\mathrm{Cr}$ & $\mathbf{R e}$ & \multirow{2}{*}{$\begin{array}{l}\mathrm{Ti} \\
\%\end{array}$} & B & Al & $\mathrm{Na}$ & $\mathbf{K}$ & Mg & Ca \\
\hline & & \multicolumn{9}{|c|}{ ppm } & & ppm & \multicolumn{5}{|c|}{$\%$} \\
\hline AW 02 & Arenisca (Colo Colo Tocota) & 0.8 & & 14 & 4 & 2 & 0.015 & 15 & 34 & 32 & 0,01 & 4 & 0.12 & 0.01 & 0.07 & 0.01 & 0.04 \\
\hline AW 03 & Brecha (Minas Krammer) & 4.2 & & 60 & 6 & 2 & 0.014 & 15 & 77 & 162 & 0,01 & 10 & 0.47 & 0.01 & 0.21 & 0.03 & 0.14 \\
\hline AW 21 & Arenisca (Minas Krammer) & 0.2 & & 6 & 7 & 2 & 0.017 & 17 & 107 & 837 & 0,01 & 7 & 0.47 & 0.01 & 0.19 & 0.02 & 0.06 \\
\hline AW 24 & Arenisca (Minas Krammer) & 1.9 & & 50 & 5 & 2 & 0.058 & 9 & 84 & 101 & 0,01 & 88 & 0.32 & 0.04 & 0.13 & 0.03 & 0.16 \\
\hline AW 25 & Mena (Minas Krammer) & 0.2 & & 470 & 3 & 2 & 0.035 & 14 & 59 & 22 & 0,01 & 139 & 0.21 & 0.02 & 0.06 & 0.03 & 0.03 \\
\hline AW 41 & $\begin{array}{l}\text { Dique de brecha (Margen derecha arroyo } \\
\text { Tocota) }\end{array}$ & 0.2 & & 3 & 11 & 2 & 0.037 & 18 & 58 & 274 & 0,01 & 12 & 0.53 & 0.01 & 0.22 & 0.04 & 0.19 \\
\hline AW 43 & $\begin{array}{l}\text { Dique de brecha (Margen derecha arroyo } \\
\text { Tocota) }\end{array}$ & 0.6 & & 3 & 19 & 3 & 0.05 & 27 & 88 & 290 & 0,01 & 14 & 1.07 & 0.02 & 0.46 & 0.06 & 0.14 \\
\hline AW 44 & $\begin{array}{l}\text { Dique de brecha (Margen derecha arroyo } \\
\text { Tocota) }\end{array}$ & 0.2 & & 3 & 3 & 2 & 0.021 & 16 & 9 & 161 & 0,01 & 3 & 0.79 & 0.02 & 0.43 & 0.03 & 0.12 \\
\hline LM 1 & Veta (Los Morteritos) & 1.3 & & 7 & 78 & 2 & 0.10 & 98 & 137 & 404 & 0,01 & 173 & 0.31 & 0.10 & 0.03 & 0.05 & 0.24 \\
\hline DAM & Veta (Dos Amigos) & 1.4 & & 158 & 27 & 2 & 0.011 & 5 & 23 & 110 & 0,01 & 7 & 0.19 & 0.02 & 0.06 & 0.03 & 0.09 \\
\hline EL 7 & Tonalita (EI Leoncito) & 0.3 & & 3 & 23 & 2 & 0.038 & 29 & 59 & 85 & 0,02 & 41 & 1.04 & 0.14 & 0.65 & 0.24 & 0.09 \\
\hline 457 & Arenisca brechoide (Quebrada Larga) & & 657 & & & & & & & & & & & & & & \\
\hline
\end{tabular}

* Au por ensayo a fuego, a partir de una muestra de 30 gramos.

Tabla 2. Resultados químicos por el método ICP-OES de las zonas geoquímicas 1 (Dos Amigos), 3 (Los Morteritos y EI Leoncito) y 4 (Tocota). Table 2. Chemical results by the ICP-OES method. Geochemical zones 1 (Dos Amigos), 3 (Los Morteritos and EI Leoncito) and 4 (Tocota).

Su valor medio es de 180 ppm y, según los resultados obtenidos por Grassi et al. (1994), en un “dique de brecha" situado al sur de esta zona 4 los contenidos llegan a superar el $0.1 \%$ de $\mathrm{Cu}$.

A partir de las observaciones microscópicas se han identificado tres pulsos de mineralización (Wetten, 1995, 1998-b) en las vetas (Tabla 5); el primero con magnetita y casiterita (Llambías and Malvicini, 1966), el segundo con magnetita - pirita - pirrotina - casiterita - calcopirita - arsenopirita cobaltífera $(0.1-0.3 \%$ Co) rutilo y una asociación de loellingita (Especie descripta por Kittl and Bellio, 1946) - arsenopirita y uno posterior con pirita, calcopirita - marcasita - esfalerita clara - oro - hematites (Fig. 10). Los minerales secundarios descriptos son covelina, calcosina, digenita, sulfatos ácidos de As-Fe-Na-N-Ca (arseniatos, jarosita-goethita-lecontita y escaso yeso) (Fig. 10). La ganga es de cuarzo y turmalina y en los bordes de las vetas es común encontrar microclina y/o sericita, illita y los sulfatos arriba citados. De los arseniatos, el más abundante es la escorodita, así como también es común la presencia de eritrina (Seguí, 1987). La roca encajante sedimentaria también ha sido receptora de parte de la mineralización, especialmente pirita en masas de jasperoides.

Entre los cuerpos de brecha cabe destacar un afloramiento tabular o dique de brecha vertical de $25 \mathrm{~m}$ de espesor máximo y disposición NO-SE (Wetten, 1995) (Figs. 3 y 4), afectado por actividad hidrotermal (Lara et al., 1993-a). Exhibe fragmentos de cuarcita con textura granular fina, subredondeados, con tamaños entre pocos $\mathrm{mm}$ y $30 \mathrm{~mm}$, frecuentemente inyectados por vetillas de cuarzo blanco y sílice coloidal. El material intersticial está compuesto mayoritariamente por cuarzo, turmalina y jarosita, con arsenopirita, óxidos de hierro, clorita, epidota (pistacita), circón y rutilo en forma subordinada. Se han reconocido tres pulsos: el primero, que depositó cuarzo, turmalina y magnetita; el segundo: cuarzo finamente bandeado, turmalina, rutilo, feldespato potásico (Wetten, 1998-b, 1999), pirita, calcopirita, arsenopirita y oro y el tercero: cuarzo. Completan esta secuencia los minerales secundarios hematites - covelina - calcosina (Tabla 5). 


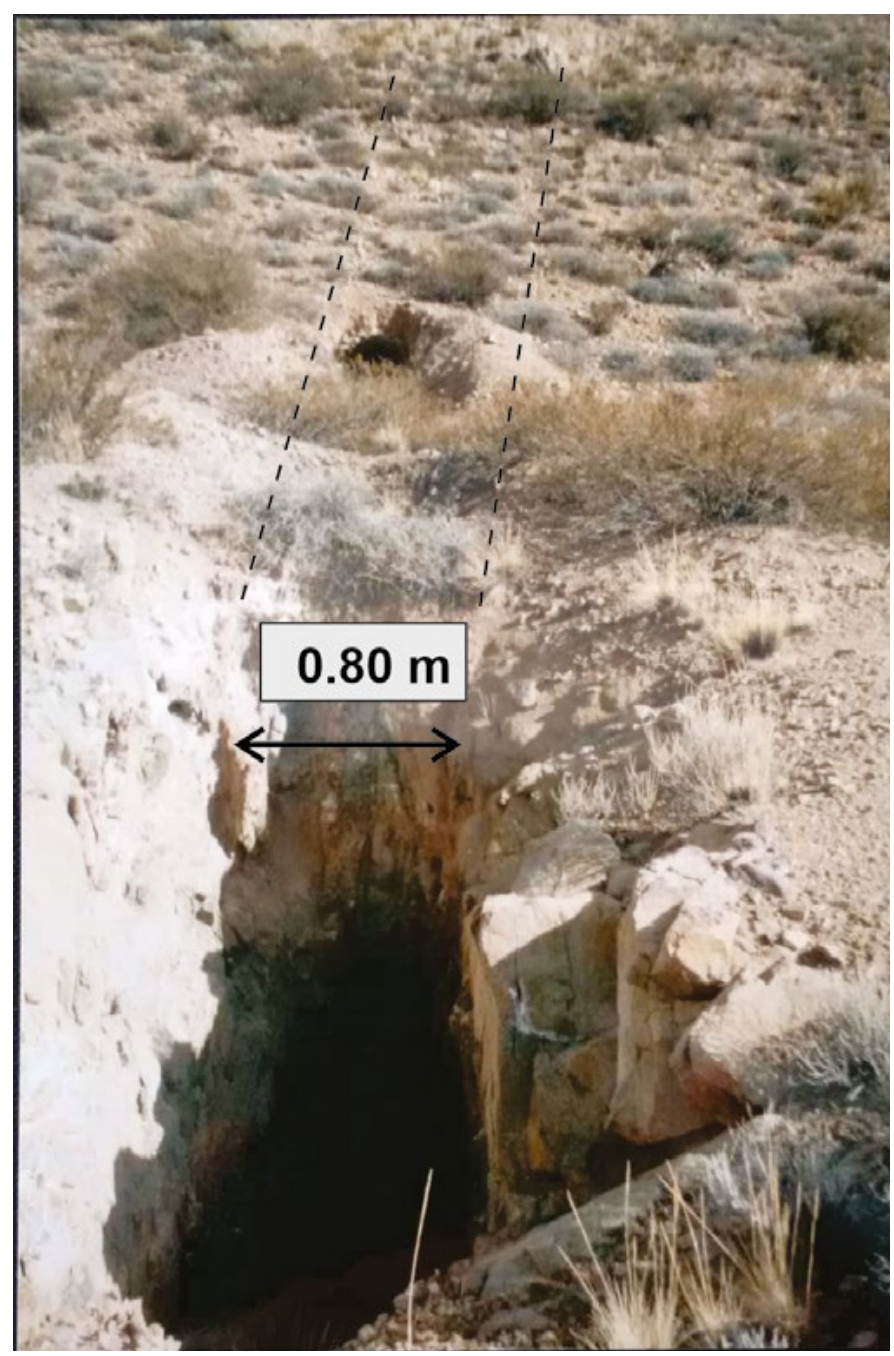

Figura 5. Galerías a cielo abierto sobre veta de dirección E-O en la mina Dos Amigos, en roca encajante granodiorítica (NE del plutón Tocota).

Figure 5: Set of uncovering galleries on the E-W vein in the Dos Amigos mine in a granodiorite wall rock (NE of the Tocota pluton).

Los minerales hipogénicos arrojaron valores de relaciones isotópicas ${ }^{34} \mathrm{~S} /{ }^{32} \mathrm{~S}$ en un rango de $3.2-3.8$ que indican, según Coleman (en Rollinson, 1994) y Hoefs (2009), una filiación granítica, aunque no se pueden descartar otras procedencias para la génesis de los citados depósitos.

Hacia el noroeste, la mina La Coruña, hospedada también en la unidad sedimentaria, tiene como elemento principal el cobre $y$, en forma subordinada, el oro (Pelichotti and Rojo, 1979). Por carecer de resultados químicos propios esta mina no ha sido asignada a una zona geoquímica en particular.

En las tablas 4 y 5 se han diferenciado tres grandes grupos de minerales paragenéticos, entre los que pueden considerarse: I) minerales silicatados de alteración hidrotermal, que ocupan tanto los bordes de las vetas como también la matriz de estructuras brechiformes y minerales de mena, como: magnetita y casiterita; II) predominio de minerales metalíferos primarios, en ganga de cuarzo y turmalina, con escasa clorita en diques piritizados que intruyen a las sedimentitas (quebrada Larga) y III) minerales primarios y secundarios en ganga de cuarzo y baritina (poco frecuente), con escasa clorita.

Tables 4 and 5 differentiate three large groups of paragenetic minerals. I) Hydrothermal alteration silicate minerals, which fill both the selvages of the veins and also the matrix in breccia type structures and ore minerals, such as magnetite and cassiterite; II) predominance of primary metalliferous minerals, in a gangue of quartz and tourmaline, with scarce chlorite in pyritized dikes that intrude the sediments (Larga creek) and III) primary and secondary minerals in a gangue of quartz and barite (rare), with low chlorite.

\section{Inclusiones fluidas}

Se identificaron asociaciones de inclusiones fluidas, en cuarzo hidrotermal, de las mineralizaciones descritas en las distintas zonas del ambiente del Plutón Tocota.

Mina Rodophis (Zona 2). El cuarzo presenta inclusiones fluidas primarias y secundarias, estas últimas

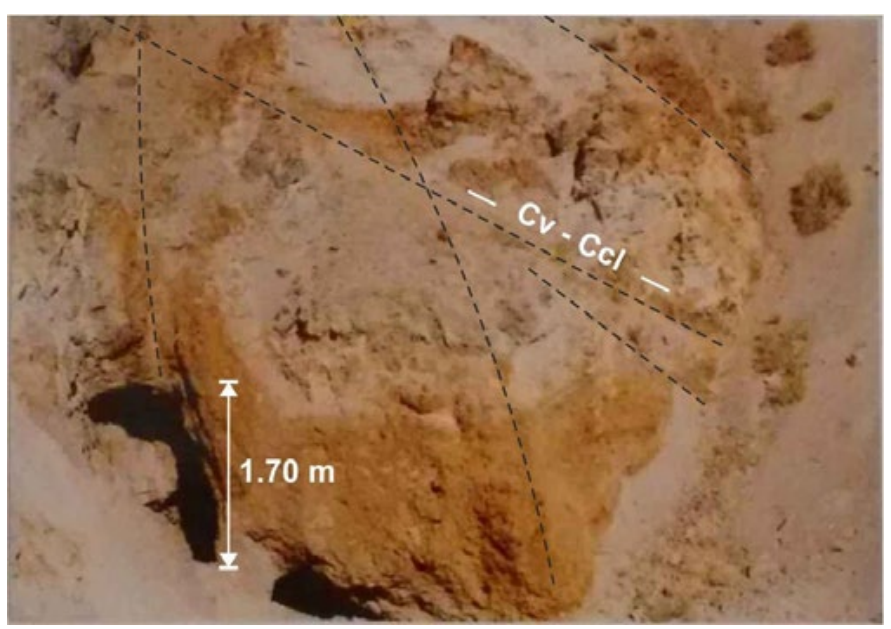

Figura 6. Antigua explotación en el nivel superior de la mina Rodophis, ejecutada mediante chiflones. Tuvo por objeto la extracción de mineral de cobre. La geometría del depósito se asemeja a un cuerpo tubular subvertical y la profundidad de la extracción supera los 20 metros. La asociación mineralógica primaria está dada por pirita, calcopirita, magnetita e ilmenita. Entre los minerales secundarios se reconocieron covelina (Cv), calcosina, tenorita, crisocola $(\mathrm{Ccl})$, rutilo, hematites, jarosita y limonitas no determinadas. La ganga es de cuarzo, calcita y yeso y la roca encajante es un monzogranito.

Figure 6: Old exploitation in the upper level of the Rodophis mine, executed through chutes. It was aimed at the extraction of copper ore. The geometry of the deposit resembles an ore chute and the depth of the extraction exceeds 20 metres. The primary mineralogical association made up of pyrite, chalcopyrite, magnetite and ilmenite. Among the secondary minerals, covellite (CV), chalcocite, tenorite, chrysocolla $(\mathrm{Ccl})$, rutile, hematite, jarosite and undetermined limonites have been identified. The gangue is composed of quartz, calcite and gypsum and the wall rock is monzogranite. 


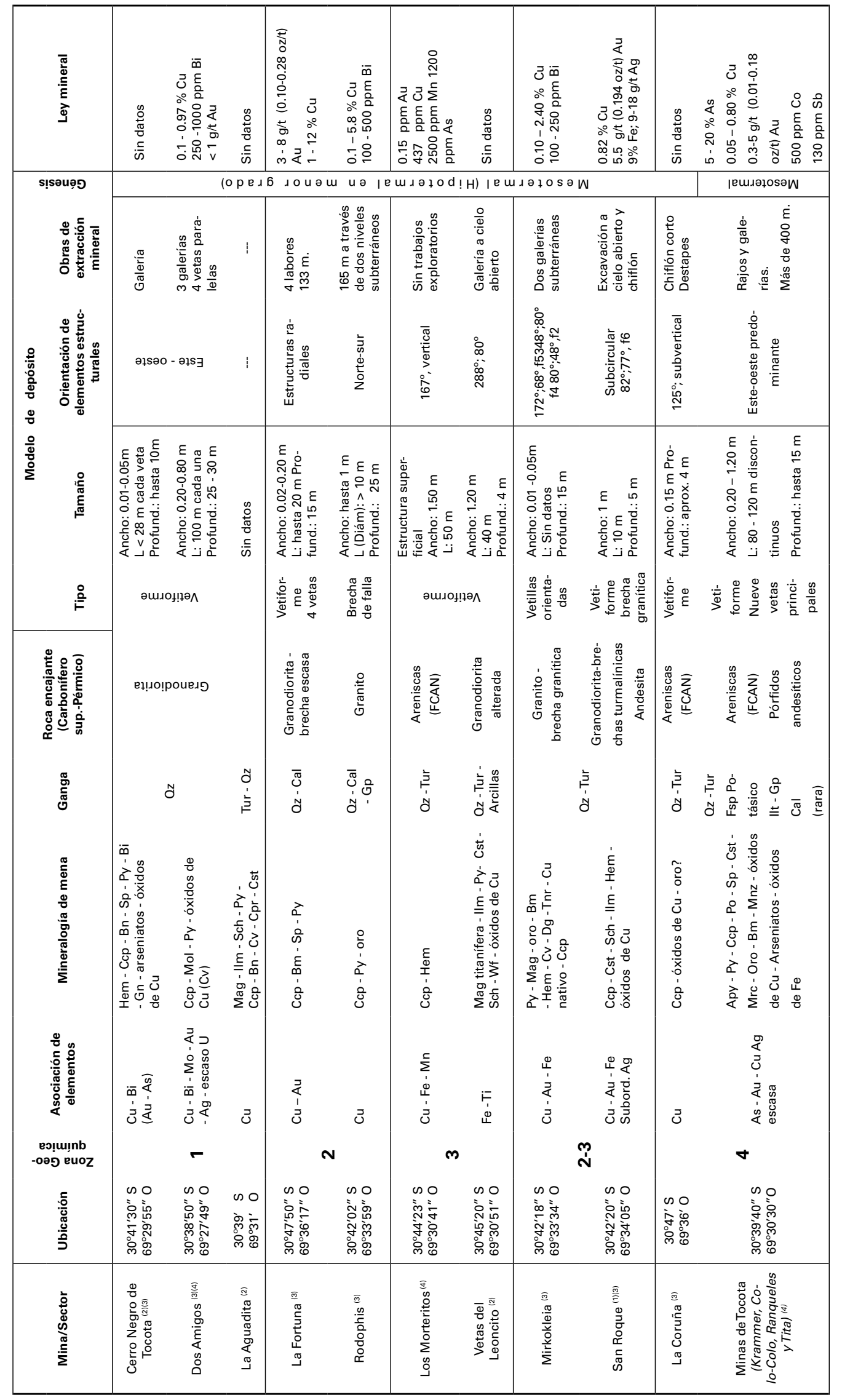

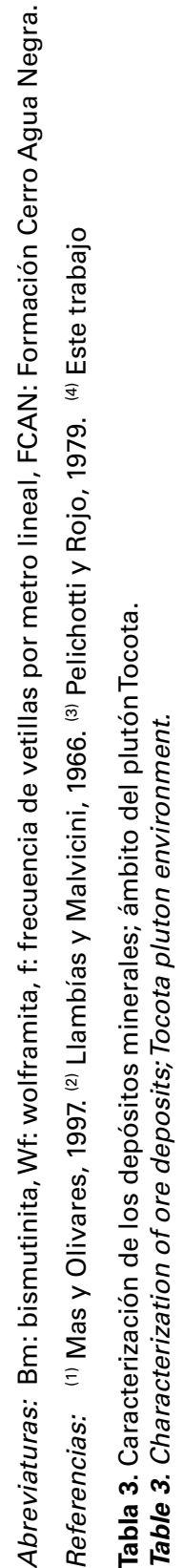



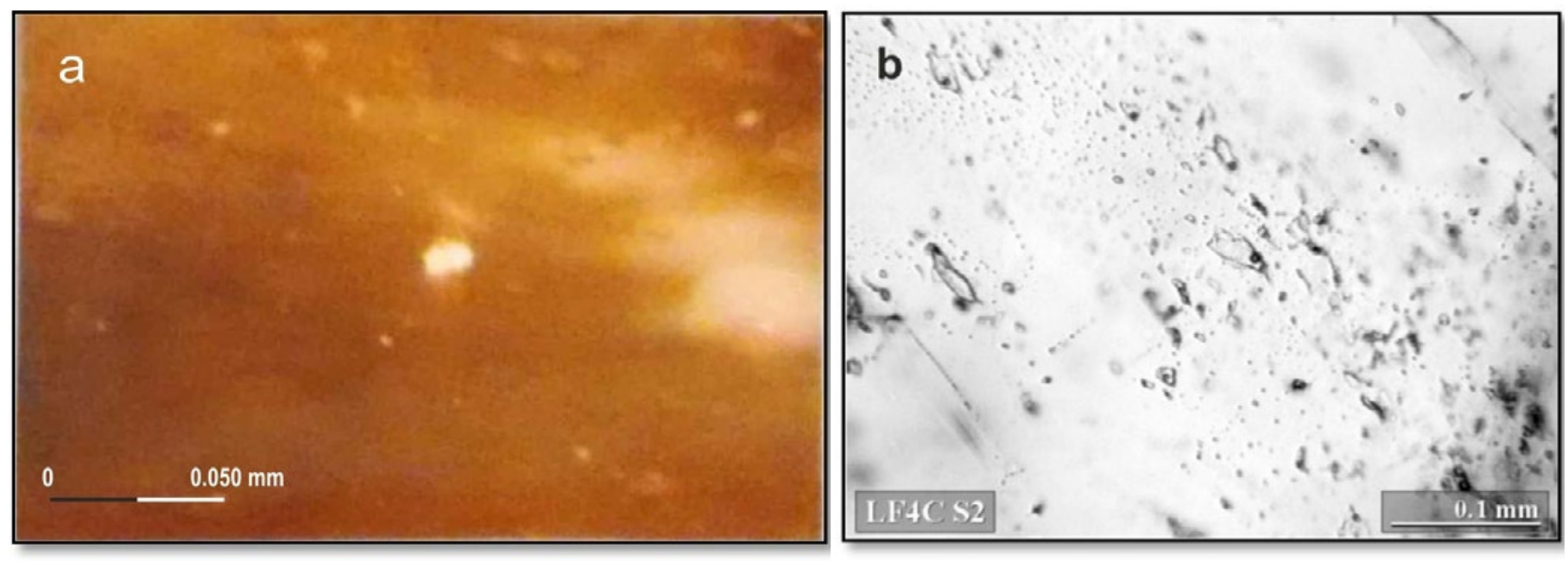

Figura 7. a) Fotomicrografía con luz polarizada plana (LPP) (50X) sobre brecha cuarzo-turmalínica. Ésta contiene granos de oro en la sílice. Uno de ellos (centro) tiene $12 \mu \mathrm{m}$ de diámetro. Procedencia: quebrada de La Fragüita; b) Fotomicrografía con LPP (20X) sobre inclusiones fluidas primarias bifásicas en cuarzo hidrotermal de la mina Rodophis.

Figure 7: a) Photomicrography with plane-polarized light (PPL) (50X) on quartz-tourmaline breccia. This one contains gold grains in the silica. One of them (centre) is $12 \mu \mathrm{m}$ in diameter. Origin: La Fragüita creek; b) Photomicrography with PPL (20X) on biphasic primary fluid inclusions in hydrothermal quartz from the Rodophis mine.

son abundantes. Son de tipo líquido + vapor y el diámetro en general es menor que $5 \mu \mathrm{m}$ (Fig. 7-b). El rango de temperaturas de homogeneización (Th) está comprendido entre $139.8^{\circ} \mathrm{C}-163.9^{\circ} \mathrm{C}$. La salinidad, obtenida a partir de Reynolds and Godstein (1995), que corresponde a las depresiones del punto de congelamiento, supera $23 \% \mathrm{NaCl}$ y la densidad que se extrajo del diagrama de fase de agua es de $1.105 \mathrm{~g} / \mathrm{cm}^{3}$ (Albinson and Reynolds, 1999).

Mina Mirkokleia (Zona 2). Las Th medidas en distintas asociaciones de inclusiones fluidas en cuarzo hidrotermal, de tipo $L+V$, ocuparon en general un rango entre $102^{\circ}$ y $249^{\circ} \mathrm{C}$ y ocasionalmente otras superaron los $400^{\circ} \mathrm{C}$.

Distrito Tocota (Zona 4). El cuarzo presenta inclusiones fluidas primarias y secundarias, estas últimas son escasas. Son de tipo líquido + vapor y líquido + vapor + sólido en una baja proporción. El diámetro de las cavidades oscila entre 2.5-10 $\mu \mathrm{m}$, excepcionalmente alcanza $30 \mu \mathrm{m}$. La salinidad de los fluidos, de las vetas del distrito Tocota, se considera moderada a alta por la presencia de cristales de halita (mayor del $26 \%$ en peso equivalente a $\mathrm{NaCl}$ ) (Figura 10-a). El factor de llenado de las vacuolas observadas en general es 0.5 . Las mediciones de temperatura, obtenidas de las asociaciones de inclusiones fluidas sobre cuarzo hidrotermal, abarcan el rango de mesotermal de temperatura media, $200^{\circ}-250^{\circ} \mathrm{C}$ (zona del arroyo Tocota), a mesotermal de mayor temperatura, $325^{\circ}-350^{\circ} \mathrm{C}$ (Mina Ranqueles, zona de la quebrada Larga, Fig. 4) (Wetten, 1998-a). La distribución de mediciones es simétrica en el primer caso (Fig. 11-a) y con sesgo negativo en el segundo (Fig. 11-b).

\section{Mineralogías de las alteraciones hidrotermales iden- tificadas}

En el área de estudio se han identificado, mediante el procesamiento de imágenes LandsatTM, varias zonas con anomalías de color y que luego fueron verificadas en el terreno con mineralogías de alteración hidrotermal, entre ellas se destacan: la quebrada La Fragüita, la quebrada Larga, la margen derecha del arroyo Tocota y el tramo medio de la quebrada del Leoncito (Fig. 4). Otras zonas de alteración hidrotermal se han identificado por las observaciones petrográficas.

\section{Alteración por metasomatismo de boro}

Los afloramientos afectados por metasomatismo de boro, expresado mediante turmalina ya sea masiva o en agregados fibrosos con diseño radial de más de 5 $\mathrm{cm}$ de diámetro, son comunes en las cercanías del eje del plutón, distribuidos en la masa granítica y en las rocas sedimentarias encajantes, siendo más frecuentes en el sector de las minas de la quebrada La Fragüita (Figs. 3, 4 y 12 a).

\section{Alteración potásica}

Esta mineralogía acompaña las paragénesis metalíferas del conjunto de depósitos de la región y es más evidente en el sector granítico de La Fragüita. Se reconoce mediante la presencia de feldespato potásico y biotita secundaria en los muros de la mineralización y rocas encajantes. Esta alteración, si bien es bastante frecuente, no desarrolla franjas de suficiente extensión para ser incluidas en el mapa.

Se presenta con intensidad leve en diques de com- 


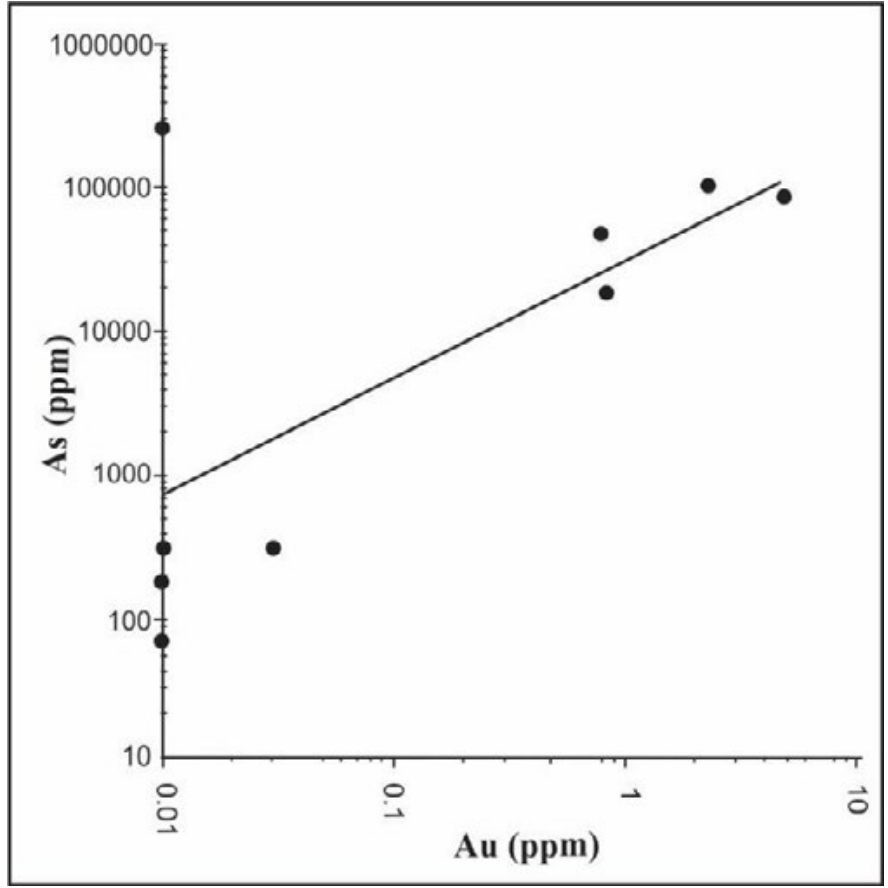

Figura 8. Correlación Au-As en vetas de la zona 4 del distrito Tocota. Los contenidos se encuentran en la Tabla 1.

Figure 8: Correlation Au-As in veins of zone 4 from Tocota district. The values are in Table 1 .

posición andesítica que intruyen la Formación Cerro Agua Negra en la quebrada Larga (Fig. 3), mediante la presencia de biotita secundaria, asociada tanto a la presencia del ya citado As como también a bajos contenidos de oro, de unos $40 \mathrm{ppb}$. Este aspecto mineralógico y geoquímico podría indicar una vinculación genética de los diques con el magmatismo Gondwánico. Una característica similar se presenta al sur, en granodioritas de la zona del Chorrillo, con diseminación de biotita secundaria (Fig. 12-d). En el extremo sur del "dique de brecha" en areniscas, en la margen derecha del arroyo Tocota (Figs. 3 y 4), se destacan zonas rojizas con distribución de ortoclasa y rutilo (Fig. 12-b), como así también con contenidos anómalos de cobre, que superan los $500 \mathrm{ppm}$. El rutilo contiene escandio, hierro, cromo y wolframio (Rabbia et al., 1996).

\section{Alteración fílica (cuarzo-sericita)}

La denominación de esta alteración se ha realizado en concordancia con lo descrito para niveles o zonas de depósitos epitermales con la presencia típica de la asociación cuarzo-illita-pirita, según Hedenquist et al. (1996).

Esta asociación ha sido detectada en coincidencia con una anomalía de color observada en bandas LandsatTM (Wetten, 1997), expuesta en la quebrada

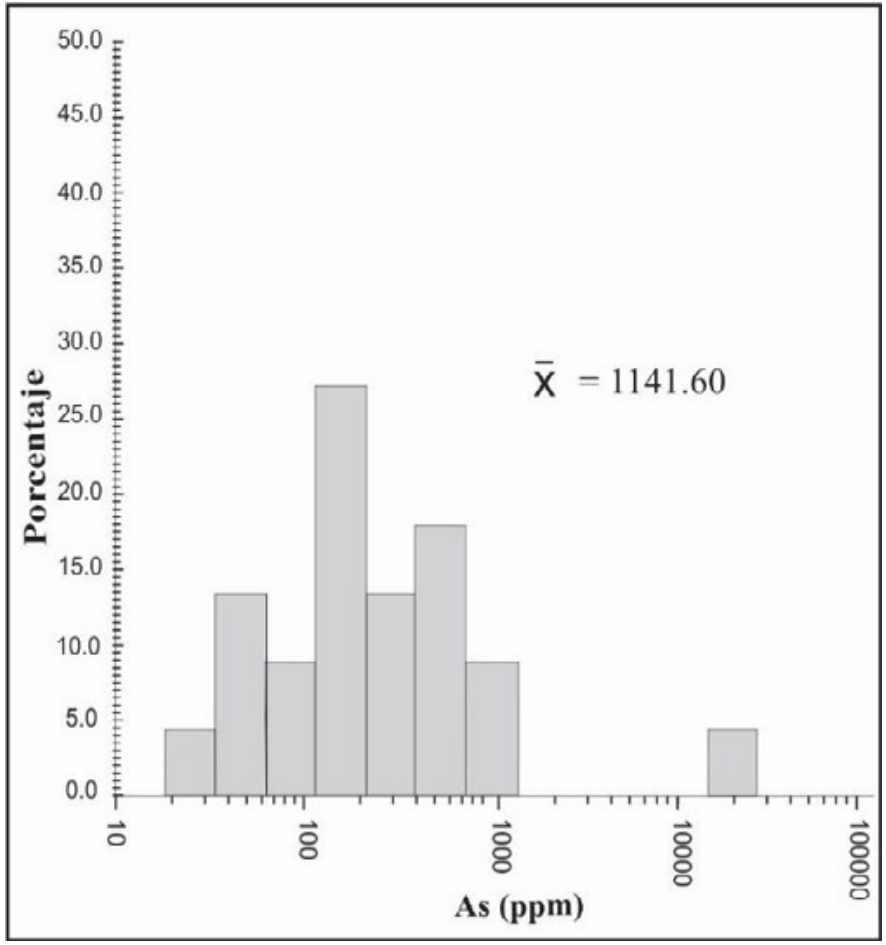

Figura 9. Distribución de As en la roca encajante de la Formación Cerro Agua Negra. Zona 4, distrito Tocota. Los contenidos se encuentran en la Tabla 1.

Figure 9. Distribution of As in the wall rock (Cerro Agua Negra Formation). Zone 4, Tocota district. The values are in Table 1.

Larga, zona norte del distrito Tocota y que abarca afloramientos de la Formación Cerro Agua Negra y diques andesíticos (Figs. 3 y 12-c). Esta zona tiene una vinculación estrecha con la mineralización de arsénico, dada la distribución geoquímica positiva ya mencionada, en especial en el encajante sedimentario (Fig. 9). La asociación cuarzo - sericita, característica de este tipo de alteración, aparece en vetas y encajante sedimentario, englobando cristales de pirita.

\section{Alteración argílica intermedia}

La denominación de la zona argílica intermedia incluye importantes cantidades de caolinita, montmoriIlonita, esmectitas o arcillas amorfas, principalmente reemplazando a plagioclasas; puede haber sericita acompañando a las arcillas; el feldespato potásico de las rocas puede estar fresco o también argilizado. Hay una significativa lixiviación de $\mathrm{Ca}, \mathrm{Na}$ y $\mathrm{Mg}$ de las rocas (Meyer and Hemley, 1967).

Esta alteración ha sido observada principalmente alrededor del ya citado dique de brecha y en afloramientos tobáceos de edad Terciario y reducida extensión, al sur de las minas Colo-Colo (Fig. 4).

En el sector del Leoncito, al sur y en el ambiente del Plutón Tocota, se reconoció un afloramiento de roca granítica con alteraciones argílica intermedia y seri- 


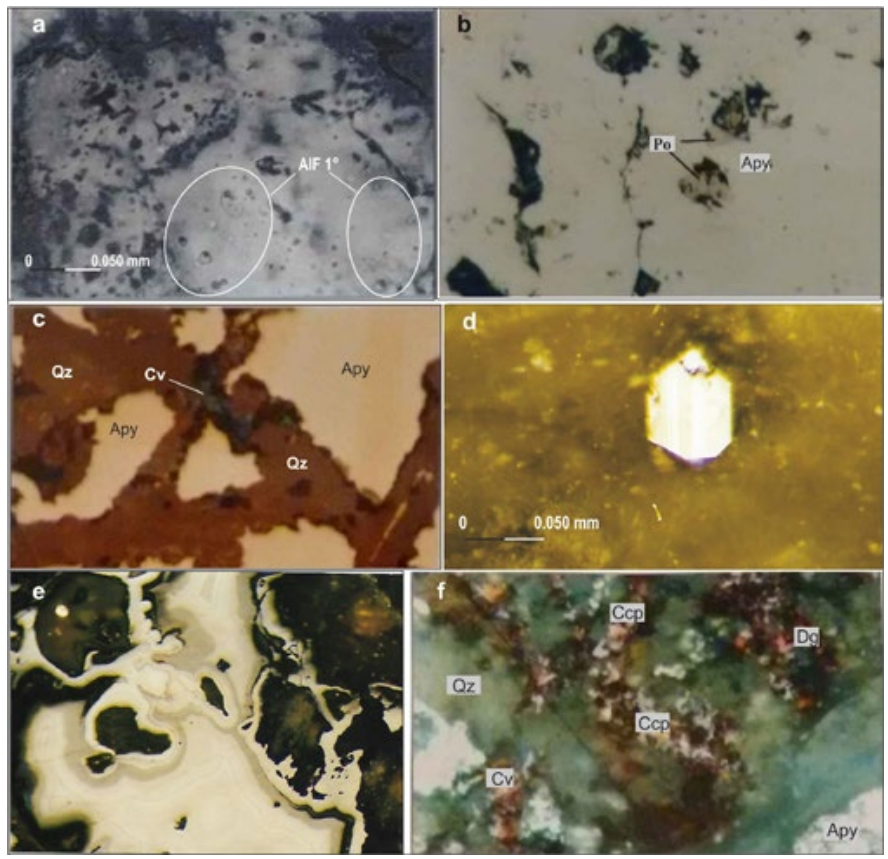

Figura 10. Muestras de cuarzo hidrotermal y de distintas fases minerales del distrito Tocota observadas bajo el microscopio óptico (a través de aire e inmersión). a) Sección delgada (50X) observada mediante luz polarizada plana (LPP), con asociaciones de inclusiones fluidas primarias bifásicas y trifásicas en cuarzo hidrotermal (AIF $1^{\circ}$ ) de la mina Colo Colo norte; b) Sección pulida (50X-LPP). Mineral de veta situado en las nacientes de la quebrada Colo Colo, constituido por pirrotina (Po) asociada a arsenopirita (Apy); c) Muestra proveniente de una veta de sulfuros $\mathrm{N} 20^{\circ} \mathrm{O} ; 40^{\circ} \mathrm{NE}, 0.10 \mathrm{~m}$ de espesor, encajada en areniscas. Exhibe granos de arsenopirita (Apy) y covelina (Cv), ésta se distribuye de modo intersticial en ganga de cuarzo $(\mathrm{Oz})$; d). Arenisca cuarzosasubarcosa con diseminación de pirita. Sector: quebrada Larga. Contiene un $10 \%$ de biotita y menor proporción de granos finos de rutilo. Al centro se destaca un cristal de marcasita; e) Sección pulida (50X-LPP) de una muestra obtenida en la mina Colo Colo norte. Se observan granos de rutilo inyectados por hematites con textura coloforme; f). Sección pulida (20X-LPP). Procede de la quebrada Larga. Se observa distribución de arsenopirita (Apy) con paragénesis posterior de calcopirita (Ccp) y productos secundarios covelina y digenita $(\mathrm{Dg})$, en ganga de cuarzo.

Figure 10. Samples containing hydrothermal quartz and different mineral phases of the Tocota district observed under the optical microscope (air and immersion modes). a) Thin section (50X) observed by plane-polarized light (PPL), with associations of primary biphasic and three-phase fluid inclusions in hydrothermal quartz from the Colo Colo north mine; b) Polished section (50X-PPL). Vein mineral located in the headwaters of the Colo Colo creek, constituted by pirrotita $(P O)$ associated with arsenopyrite (Apy); c) Sample from a sulfide vein $\mathrm{N}^{\circ} \mathrm{W} ; 40^{\circ} \mathrm{NE}, 0.10 \mathrm{~m}$ thick, hosted in sandstones. It exhibits grains of arsenopyrite (Apy) and covellite $(\mathrm{Cv})$, which is distributed interstitially in quartz gangue $(\mathrm{Oz}) ;$ d). Quartz-subarkose sandstone with disseminated pyrite. Sector: Larga creek. It contains $10 \%$ biotite and a smaller proportion of fine rutile grains. A marcasite crystal stands out in the center; e) Polished section (50X-PPL) of a sample obtained at the Colo Colo north mine. Rutile grains injected by hematite with colloform texture are observed; f). Polished section (20X-PPL). Sample collected in the Larga creek. Distribution of arsenopyrite (Apy), with later chalcopyrite paragenesis $(C c p)$ and secondary products covellite and digenite $(D g)$ in quartz gangue is observed. cítica, con hematites rellenando fisuras (Fig. 4). Esta roca granítica, portadora de rutilo e ilmenita, presenta además mineralización de pirita y oro de grano fino en ganga de cuarzo y turmalina. Los contenidos de oro son ligeramente elevados (10 ppb).

\section{Alteración propilítica}

La denominación de la zona propilítica incluye la presencia de epidota y/o clorita y ausencia de un apreciable metasomatismo catiónico o lixiviación de álcalis; comúnmente se presentan también albita, calcita y pirita (Meyer and Hemley, 1967).

Esta alteración, dada principalmente por la asociación pirita - clorita, es de intensidad baja a moderada y ha sido reconocida en diques de composición intermedia del plutón y su encajante sedimentario.

\section{Discusión}

Los yacimientos metalíferos importantes, en el sector sur del Batolito de Colangüil pueden ser asignados a dos épocas metalogénicas diferentes: la Gondwánica, de edad Carbonífero a Pérmico-Triásico y la Andina, de edad Neógeno (Malvicini and Caminos, 1994). Los yacimientos metalíferos Gondwánicos tienen claros exponentes en el área de estudio, con paragénesis características en los ambientes de la Formación Cerro Agua Negra y del plutón Tocota. Los yacimientos metalíferos Andinos tienen sus manifestaciones de interés económico más hacia el norte, a partir del arroyo de Chita (Figs. 1 y 2), a los que se suma el resto de pórfidos neógenos de la Cordillera Frontal, de interés por sus contenidos de metales preciosos.

En lo que respecta a los dominios o zonas de mineralizaciones metálicas (zonas 1, 2, 3 y 4), es necesario hacer un breve análisis del modelo expuesto. Ambas unidades (granito y rocas sedimentarias) consideradas del Ciclo Gondwánico, contienen sustancias metalíferas particulares. La migración de fluidos mineralizadores ha sido principalmente por el mecanismo de inyección de vetas $y$, en menor medida, por brechificación de las rocas encajantes. Otro mecanismo asociado a este proceso ha sido el de difusión y/o metasomatismo.

Las tonalitas y granodioritas de este plutón están intruidas por cuerpos de granitos y leucogranitos normalmente rosados. Estos granitos afloran desde la zona de La Fragüita hasta la quebrada del Rincón Seco (Fig. 3) y es en aquella zona donde exhiben la mayor concentración metalífera. $\mathrm{Cu}, \mathrm{Au}$ y Fe fueron explotados a través de galerías poco someras y labores de alta inclinación (chutes) (Tabla 3, Fig. 4). Estas extracciones minerales se hicieron desde vetas y depósitos de forma tubular o clavos. Es frecuente que brechas graníticas y sectores con abundante feldespato potásico y turmalina acompañen la mineralización de la citada zona de La Fragüita. El arsénico es anómalo en las rocas graníticas (Tabla 2, mina Dos 


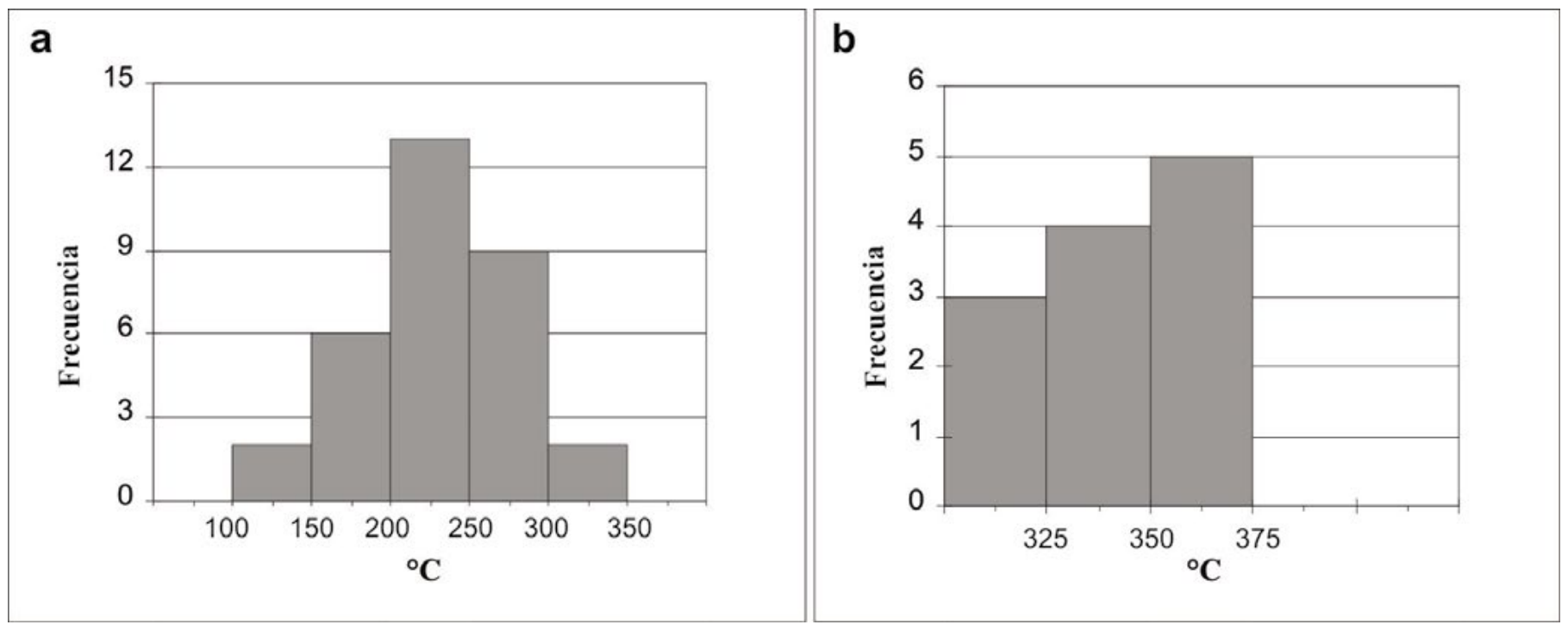

Figura 11. Temperaturas de homogeneización de inclusiones fluidas. a) Minas Krammer y Colo Colo. b) Mina Ranqueles Figure 11. Homogenization temperatures of fluid inclusions. a) Krammer and Colo Colo mines. b) Ranqueles mine

Amigos) pero no constituye depósitos económicos. La unidad sedimentaria, encajante del plutón, exhibe mineralización con vetas y brechas hidrotermales. As, $\mathrm{Cu}$ y $\mathrm{Bi}$ fueron explotados en esta unidad, donde el distrito Tocota (Zona 4) fue fuertemente minado para obtener mineral de arsénico (Tablas 1 y 3 ).

Es probable que después de la consolidación del plutón, fluidos hidrotermales ascendentes, mezclados con aguas meteóricas, hayan circulado y formado, a través de planos de debilidad, zonas de metasomatismo con feldespato potásico, boro y también vetas metálicas en los granitos.

Este modelo de cristalización mineral, que se pretende establecer para un entorno de intrusiones graníticas, podría reforzarse teniendo en cuenta tanto los coeficientes de partición como la forma de la intrusión. Los coeficientes de los elementos característicos de la región son: $\mathrm{Mn}-\mathrm{As}>2$ y $\mathrm{B}-\mathrm{Cu}>10$. Estos valores son indicativos de la eficiencia de extracción de fluido de un plutón (Audetat, 2019). También se debería tener en cuenta el alto grado de erosión que afecta la porción centro-sur. En esta zona, las ocurrencias de mineral de $\mathrm{Cu}$ son comunes, aunque no lo son para As, cuya ocurrencia es característica en el distrito Tocota (Zona 4, unidad sedimentaria, Fig. 4).

A partir de los cálculos de salinidad y las estimaciones de densidad de las inclusiones fluidas de cuarzo hidrotermal, la termometría estaría indicando profundidades de emplazamiento de la mineralización someras (mayor de $1000 \mathrm{~m}$ ) para estos depósitos relacionados con los granitos del Plutón Tocota (Wetten, 1998-a-b, 2020), lo cual sería concordante con la profundidad determinada por Sato (1989) y Llambías and Sato (1990), de $1.3 \mathrm{~km}$ para el emplazamiento del plutón Chita (Fig. 1). En el caso de la mineralización de la roca encajante sedimentaria, relacionada con fluidos de menor densidad, esa profundidad sería menor.
En la zona 4, la presencia de asociaciones minerales secundarias, a partir de minerales primarios conteniendo $\mathrm{Cu}-\mathrm{As}-\mathrm{Co}$, son indicadores de la zona de oxidación y su distribución coincide con el desarrollo vertical limitado de la explotación (Wetten, 1995, 1998-b). El acuñamiento de los depósitos metalíferos en vetas, sumado a la ausencia de estudios exploratorios, fue uno de los condicionantes que motivó el abandono de las minas (Wetten, 1999).

El magmatismo mioceno, presente en el norte del plutón Tocota (Formación Lomas Claras en las cercanías de los sectores de las minas Colo Colo y la quebrada Larga; Figs. 1, 3 y 4) y que constituiría la finalización de una larga actividad magmática en la región, no evidencia contenidos metalíferos anómalos ni relación cogenética con los depósitos de la citada cuenca. En este sector, la continuidad de las vetas del distrito Tocota ha sido interrumpida bruscamente por la intrusión de domos y diques subvolcánicos de roca andesítica de la Formación Lomas Claras (Ciclo Andino). Las vetas como así también sus encajantes y los fragmentos de roca de las brechas hidrotermales contienen elementos minerales como turmalina, microclina y monacita y están ausentes materiales volcánicos que podrían representar un tipo de vínculo genético con el citado magmatismo.

\section{Conclusiones}

Los depósitos minerales están espacialmente vinculados a una zona con magmatismo Gondwánico y Andino (Llambías and Sato, 1990; Malvicini and Caminos, 1994). El magmatismo Gondwánico generó rocas graníticas que intruyeron a rocas sedimentarias. Sobre estas unidades de rocas, posteriormente, se formaron las mineralizaciones.

La mineralización del Ciclo Gondwánico es epige- 
nética, su patrón de distribución está regido por: 1) mayoritariamente inyección de fluidos en fallas y diaclasas, 2) brechas de falla y brechas magmáticas hidrotermales y 3 ) diques de composición andesítica con bajos contenidos metálicos. Las venas minerales tienen variada orientación, en todos los sectores de estudio se observó un predominio de las direcciones ENE y ONO y, en forma subordinada, la NNO.

Las dos unidades principales, granitoides y roca
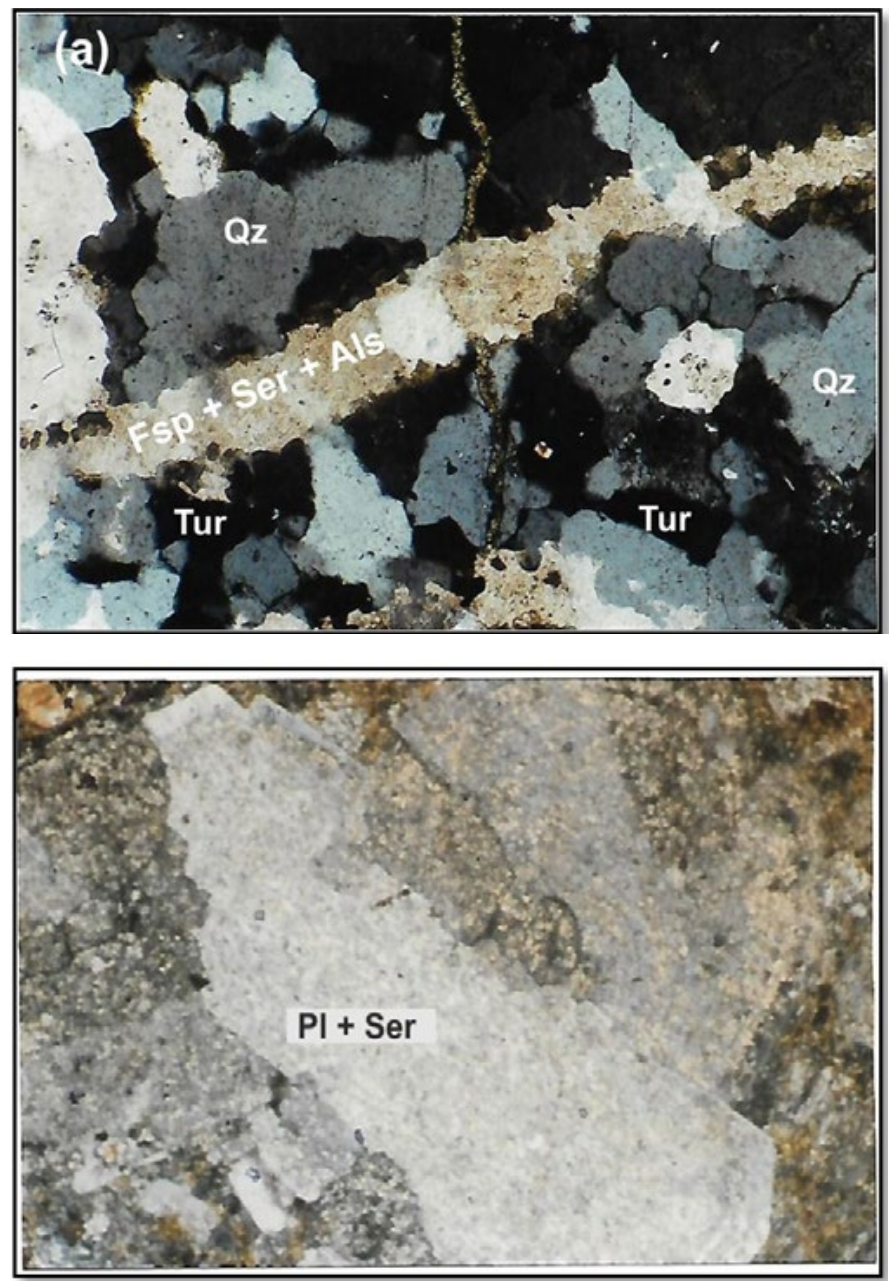

encajante sedimentaria, se caracterizan por exhibir una distribución geoquímica bien evidenciada de los metales $\mathrm{Cu}$, Au y As y en mayor o menor medida, de Fe y $\mathrm{Bi}$. Se han identificado cuatro zonas geoquímicas levemente diferentes: tres en los granitos y una en la unidad sedimentaria (Fig. 4).

Zona 1: dominada por el cobre, al que se asocian $\mathrm{Bi}$, Mo y As. El Cu está presente con contenidos elevados, frecuentemente de varios cientos de ppm y, ocasio-
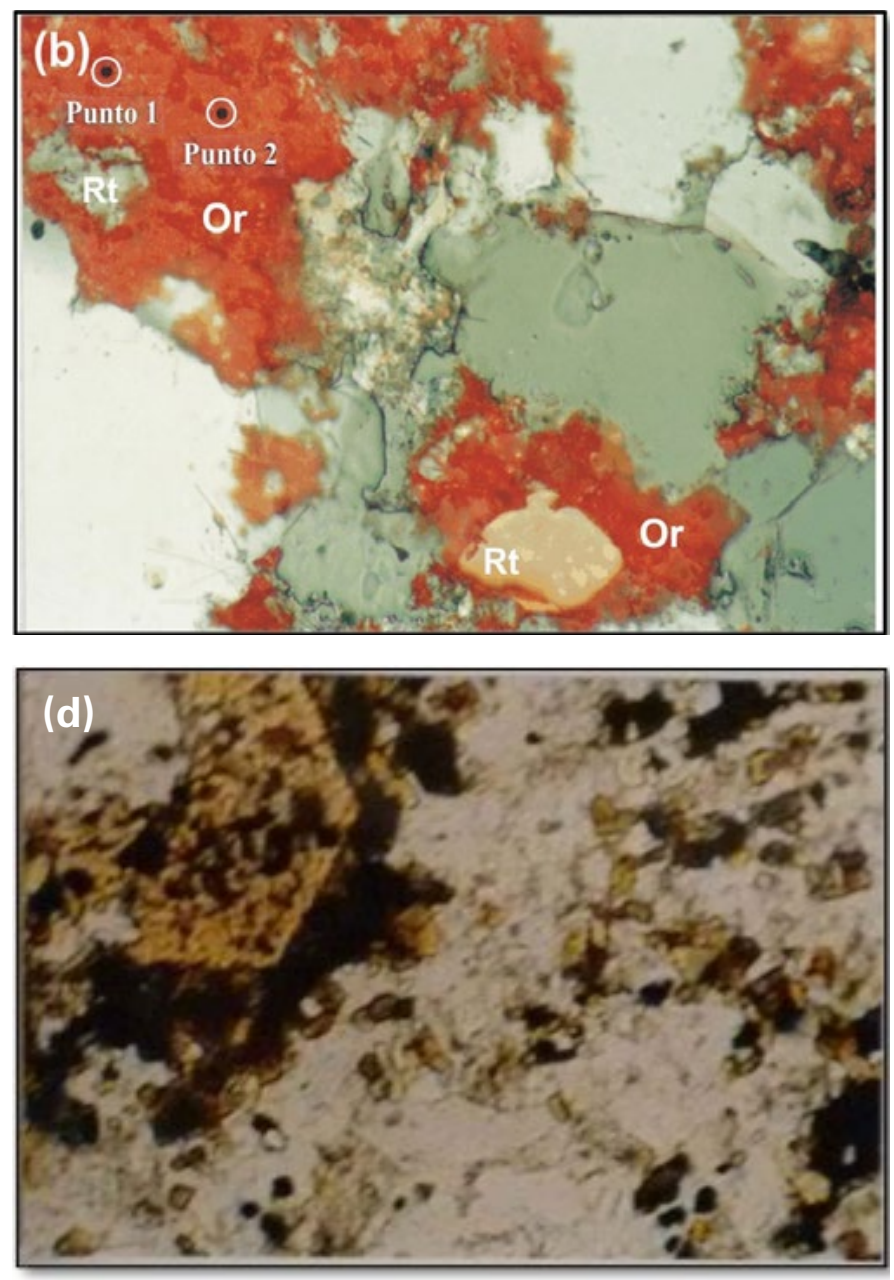

Figura 12. (a) Fotomicrografía de granito turmalínico (10X), mediante luz polarizada cruzada (LPC). Venilla de feldespato potásico (Kfs), con parches de sericita (Ser) y arcillas (Als), que corta el agregado de cuarzo (Oz) y turmalina (Tur). Procedencia: quebrada La Fragüita; (b) Fotomicrografía de una muestra de brecha hidrotermal en arenisca cuarzosa como soporte (10X), mediante luz polarizada paralela (LPP). Se destacan la fase roja consistente en ortoclasa (Or) y granos irregulares de rutilo (Rt). En la esquina superior izquierda se marcaron los puntos 1 y 2 para las determinaciones con microsonda. Procedencia: Dique de brecha (Sur del distrito Tocota); (c) Fotomicrografía de pórfido andesítico (2.5X - LPC). En el centro, cristales de plagioclasa (oligoclasa-andesina) sericitizados (PI+Ser). Procedencia: quebrada Larga, norte del distrito Tocota; (d) Muestra de granodiorita (10X-LPP) con diseminación de biotita secundaria (Bt), además se destacan minerales opacos asociados a nidos de biotita y hornblenda (Hbl) como mineral accesorio de grano grueso (esquina superior izquierda). Procedencia: quebrada del Chorrillo.

Figure 12. (a) Photomicrograph of tourmalinic granite (10X), using crossed polarized light (CPL). Veinlet of potassic feldspar (Kfs), with sericite (Ser) and clay (Als) patches, that cuts the aggregate of quartz (Oz) and tourmaline (Tur). Provenance: La Fragüita creek; (b) Photomicrograph of a hydrothermal breccia sample in quartz sandstone as support (10X), through plane-polarized light (PPL). The red phase consists of orthoclase (Or) and irregular rutile grains (Rt). In the upper left corner, points 1 and 2 were marked for microprobe determinations. Provenance: Breccia dike (South of the Tocota district); (c) Photomicrograph of andesitic porphyry (2.5X - CPL). In the center, crystals of plagioclase (oligoclase-andesine) with sericite (PI+Ser). Provenance: Larga Creek, north of the Tocota district; (d) Photomicrograph of granodiorite (10X-PPL) with a distribution of secondary biotite (Bt), also stand out opaque minerals associated with biotite sittings and hornblende ( $\mathrm{Hbl}$ ) as an accessory mineral of coarse-grained (upper left corner). Provenance: Chorrillo creek. 


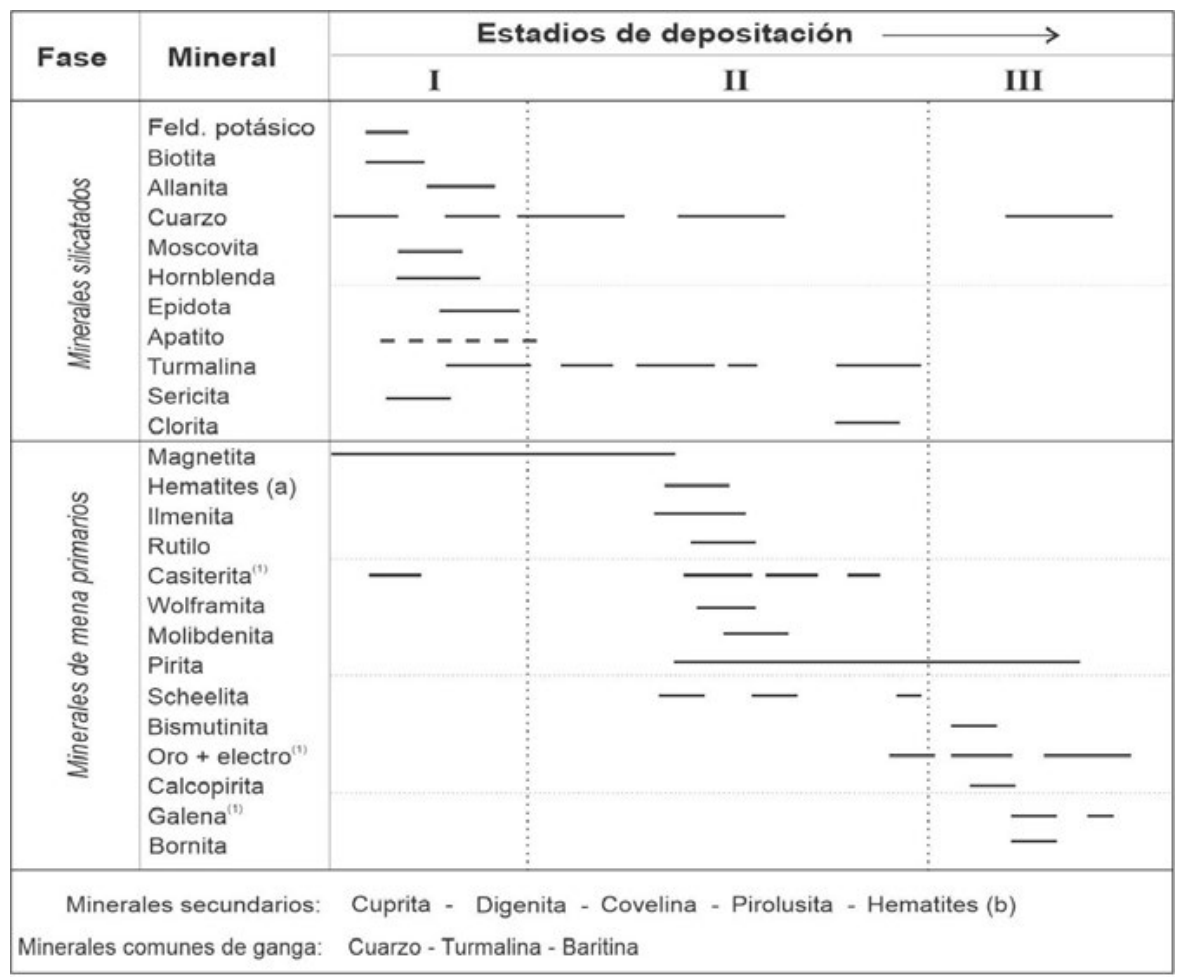

Tabla 4. Asociaciones paragenéticas reconocidas en las zonas cuprífero - ferríferas (Zonas geoquímicas 1, 2 y 3) del plutón Tocota. Table 4. Recognized paragenetic associations in the copper-ferriferous zones (Geochemical Zones 1, 2 and 3) of the Tocota pluton.

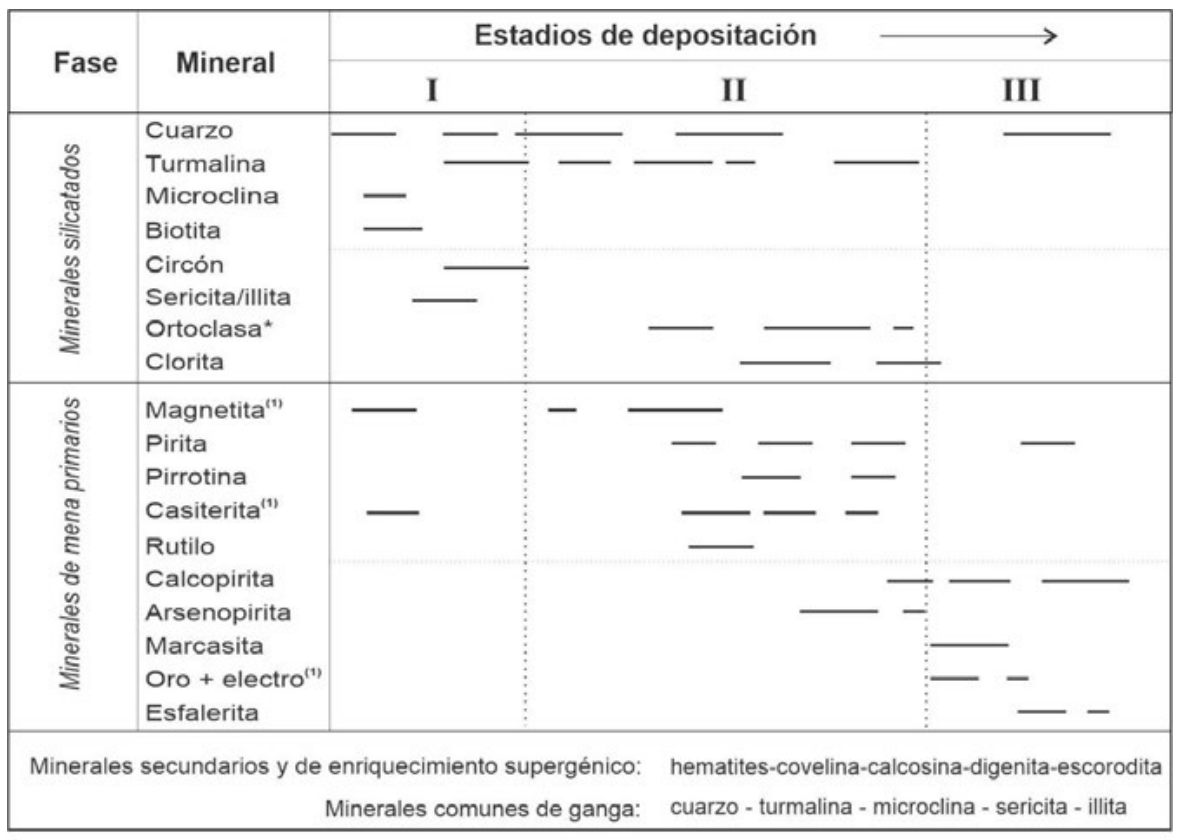

(1) Llambias y Malvicini, 1966 *Fase mineral notoria en el dique de brecha (Fig. 4, margen derecha del arroyo Tocota)

Tabla 5. Etapas de mineralización y alteración hidrotermal en el distrito Tocota (Zona geoquímica 4), observadas en las vetas y en un importante dique de brecha mineralizado.

Table 5. Stages of mineralization and hydrothermal alteration in the Tocota district (Geochemical zone 4), observed in the veins, and on a significant ore breccia dike. 
nalmente, con contenidos económicamente viables, que comúnmente superan el $1 \%$ (Tablas 2 y 3 ). Esta asociación se localiza con concentraciones mayores hacia el borde oriental del plutón Tocota.

Zona 2-La Fragüita: se trata de vetas o filones en la unidad granítica, próximos al eje del plutón (Fig. 4). Poseen una asociación metalífera de $\mathrm{Cu}, \mathrm{Fe}, \mathrm{Bi}, \mathrm{Au}$ y otra menos concentrada de Ag, Mo, As, Fe y U (Tabla 3 y Fig. 4), con poca diseminación en las rocas encajantes como así también en brechas turmalínicas cercanas a los depósitos. El mayor número de explotaciones cupríferas se halla en la facies monzogranítica.

Zona 3: En las quebradas de Los Morteritos y El Leoncito y en las minas Mirkokleia y San Roque el hierro es el elemento más importante. Además, se constató la presencia de anomalías positivas geoquímicas en varios elementos: $\mathrm{Cu}, \mathrm{As}, \mathrm{Au}, \mathrm{Ag}, \mathrm{Mn}, \mathrm{Fe}$, en menor grado, Re y La.

Zona 4-distritoTocota: cuenta con un importante número de minas situadas en la formación Cerro Agua Negra y, ocasionalmente, en diques del plutón Tocota como encajante. Esta zona tiene una distribución geoquímica relativamente homogénea, con algunas variaciones. El arsénico es el elemento más abundante y también el de distribución más uniforme (Tablas 1, 3 y Fig. 4). De forma subordinada, se distribuyen $\mathrm{Cu}$, $\mathrm{Fe}, \mathrm{Ag}, \mathrm{Sb}, \mathrm{Mo}, \mathrm{Bi}, \mathrm{Re}$ y trazas de La (Tablas 1 y 2). El Au está correlacionado en forma positiva con $\mathrm{Sb}, \mathrm{As}$, Mo y Ag. Tanto el $\mathrm{Cu}$ como estos últimos elementos son anómalos, a excepción de $\mathrm{Ag}$, que es levemente anómala.

La geometría de las estructuras mineralizadas, observada en las citadas zonas es: zona 1) vetiforme, con orientación predominante E-O (Dos Amigos), zona 2) lenticular curvada, de depósitos mineralizados tubulares o tipo clavo (mina Rodophis) y enjambres de vetillas (nacientes de la quebrada del Chorrillo), zona 3) tabular (vetas de Los Morteritos, El Leoncito) y zona 4) vetiforme, lenticular y cuerpos de brecha. La orientación predominante de vetas es aproximadamente E-O (Colo-Colo, Krammer). La mineralización en las rocas de caja comúnmente se manifiesta por relleno de juntas de baja densidad y espesores milimétricos, acompañada por diseminación metalífera y silicificación fuerte.

Los afloramientos de brecha se han distinguido en todo el ámbito del Plutón Tocota. El sector de la quebrada La Fragüita muestra mayor abundancia de tales cuerpos, donde se reconocieron brechas de tipo cuarzo-turmalina, graníticas e hidrotermales.

Las asociaciones metalíferas reconocidas en los granitoides son: zona 1) calcopirita como primario y covelina, calcosina, malaquita, azurita y jarosita como secundarios, en ganga de cuarzo, turmalina y escasa calcita, zona 2) pirita, calcopirita, magnetita, ilmenita, cobre nativo-cuprita-bismutinita (mina Mirkokleia), casiterita-scheelita (mina San Roque) y oro y minerales secundarios: covelina, calcosina, tenorita, crisocola, rutilo, hematites, jarosita y limonitas no determi- nadas, en ganga de cuarzo, calcita, yeso, moscovita (mina San Roque), turmalina, titanita, allanita y baritina (mina Mirkokleia), zona 3) principalmente magnetita y hematites, en ganga de cuarzo y turmalina. Las asociaciones en el encajante sedimentario corresponden a la zona 4) magnetita, casiterita, arsenopirita, pirita, pirrotina, calcopirita, arsenopirita cobaltífera, marcasita, esfalerita clara y oro, minerales secundarios: covelina, calcosina, digenita, sulfatos ácidos de As-Fe-Na-N-Ca, en ganga de cuarzo, turmalina, microclina y/o sericita, illita y ortoclasa férrica.

Las etapas de mineralización incluyen tres grupos de minerales paragenéticos: fase silicatada (minerales de alteración hidrotermal), minerales de mena primarios y minerales de mena secundarios. En la mayoría de los casos cada grupo pertenece a un estadio de evolución temporal definido $y$, en menor proporción, se reconocieron fases con tres estadios de depositación (cuarzo, turmalina, hematites).

De las fases de mineralización identificadas, se interpretó que la más antigua es de alta temperatura (mayor de $400^{\circ} \mathrm{C}$ ) y las restantes son de baja temperatura (menor que $250^{\circ} \mathrm{C}$ ). Muestras de cuarzo hidrotermal, provenientes de la zona geoquímica No. 2 (Fig. $4)$, contienen asociaciones de inclusiones fluidas primarias del tipo L+V (Fig. 7-b), en general con un rango de temperaturas de homogeneización (Th) entre $139.8^{\circ} \mathrm{C}-249^{\circ} \mathrm{C}$. La salinidad de los fluidos, en la zona geoquímica No. 4, se considera moderada a alta por la presencia de cristales de halita (mayor del $26 \%$ en peso equivalente a $\mathrm{NaCl}$ ) (Figura 10-a). Las mediciones realizadas sobre inclusiones fluidas, en esta zona, abarcaron rangos de Th de $200^{\circ}-250^{\circ} \mathrm{C}$ (minas próximas al arroyo Tocota) y de $325^{\circ}-350^{\circ} \mathrm{C}$ (Mina Ranqueles, quebrada Larga, Figs. 4, 11-a-b).

Varias zonas, con diferente geometría y extensión, fueron verificadas en el terreno con mineralogías de alteración hidrotermal, entre ellas se destacan: la quebrada La Fragüita, la quebrada Larga, la margen derecha del arroyo Tocota y el tramo medio de la quebrada del Leoncito (Fig. 4). La zona con metasomatismo de boro, mediante turmalina ya sea masiva o en agregados fibrosos, es común en las cercanías del eje del plutón, distribuida en la masa granítica y en las rocas encajantes sedimentarias, siendo más marcada en el sector de las minas de la quebrada La Fragüita (Fig. 4). La alteración potásica ha sido reconocida mediante la presencia de feldespato potásico y biotita secundaria en los muros de la mineralización y rocas encajantes (Granitos de La Fragüita). En el extremo sur del "dique de brecha" en areniscas, en la margen derecha del arroyo Tocota (Fig. 4), se destacan zonas rojizas con distribución de ortoclasa y rutilo (Fig. 12-b), como así también con contenidos anómalos de cobre, que superan los 500 ppm. La alteración fílica (cuarzo-sericita) ha sido detectada en la quebrada Larga (Figs. 4 y 12-c), abarca vetas, afloramientos de la Formación Cerro Agua Negra y diques andesíticos, además engloba cristales de pirita. La alteración argílica intermedia 
ha sido observada principalmente alrededor del ya citado dique de brecha y en afloramientos tobáceos de edad Terciario y de reducida extensión, al sur de las minas Colo-Colo (Fig. 4). Además, en el sector del Leoncito, al sur y en el ambiente del plutón Tocota, se reconoció un afloramiento de roca granítica (Fig. 4) con alteraciones argílica intermedia y sericítica, con hematites rellenando fisuras, pirita y oro de grano fino en ganga de cuarzo y turmalina.

Se define la existencia de un metalotecto principal, tardí-magmático, expresado comúnmente mediante vetas por el mecanismo de intrusión, y en la roca huésped sedimentaria, en proximidades de la unidad granítica. La mineralogía de las vetas, las temperaturas de las mineralizaciones demasiado bajas en comparación con las de cristalización de los magmas graníticos y los resultados isotópicos de $\delta^{34} \mathrm{~S}$ no permiten establecer, con total seguridad, una relación directa entre magmatismo granítico y mineralizaciones. Serían necesarios estudios más detallados sobre la petrogénesis de estos granitos para poder establecer o descartar alguna relación genética con las mineralizaciones.

\section{Agradecimientos}

El autor expresa su agradecimiento al profesor CarIos Esteban Castro (UNSJ-Argentina), por la lectura crítica del manuscrito, a los investigadores del Instituto de Investigaciones Mineras (UNSJ) por el análisis de muestras de mineral en el laboratorio y por la supervisión en las tareas de procesamiento de imágenes Landsat TM, a colegas del Instituto de Geología (UNSJ) y a la profesora Milka K. de Brodtkorb ${ }^{\dagger}$ (UBA) por la observación de especímenes de rocas granitoides y de minerales opacos, respectivamente.

\section{Referencias}

Albinson, T. and Reynolds, J.T. 1999. Notas para Seminario-Taller de Inclusiones Fluidas.

Aparicio, E. P. 1969. Contribución al conocimiento de la edad de los sedimentos del arroyo de Agua $\mathrm{Ne}$ gra, Departamento de Iglesia, San Juan, República Argentina. Revista de la Sociedad Geológica Argentina, 31(3), 190-193)

Audetat, A. 2019. The Metal Content of Magmatic-Hydrothermal Fluids and Its Relationship to Mineralization Potential. Society of Economic Geologists, Inc. Economic Geology, v. 114, No. 6, pp. 1033-1056

Baraldo J., Wetten A., Olivares L. and Moyano E. 2002. Análisis de la fracturación andina en un sector de Cordillera Frontal, provincia de San Juan. Actas del XV Congreso Geológico Argentino CD-ROM. Artículo No. 274. 5pp.

Bastías, H. E. 1991. Complejo volcánico Olivares: un gran evento magmático mioplioceno en los Andes a $30^{\circ}$ de Latitud sur. 6to Congreso Geológico Chileno. Viña del Mar. Actas volumen 1; 520 - 524.

Benavídez de Albar Díaz, M. 2016. Oro y plata en la historia minera de San Juan. Editorial UNSJ. ISBN 978-987-3984-22-8.

Borelli, D., Segal, S., Puglisi, C. and Pina, J. 1992. Características metalogénicas y evaluación económica de las manifestaciones auro-argento-estanníferas "Antecristo", provincia de San Juan, Argentina. 4to Congreso Nacional de Geología Económica y 1 er Congreso Latinoamericano de Geología Económica. Córdoba, Argentina, 6-12.

Busquets, P., Méndez-Bedia, I., Gallastegui G., Colombo, F., Cardó, R., Limarino O., Heredia N. and Césari, S. N. 2013. The relationship between carbonate facies, volcanic rocks and plant remains in a late Palaeozoic lacustrine system (San Ignacio Fm, Frontal Cordillera, San Juan province, Argentina). International Journal of Earth Sciences (Geol Rundsch) 102:1271-1287

Busquets, P., Limarino, C. O., Cardó, R., Méndez-Bedia, I., Gallastegui, G., Colombo, F., Heredia, N., and Césari, S., N. 2013. The neopaleozoic of the Sierra de Castaño (Andean Cordillera Frontal, San Juan, Argentina): Tectonic and paleoenviromental reconstruction. Andean Geology 40 (1): 172-195. January, 2013

Cardó, R., Díaz I. N., Cegarra, M., Heredia, N., Rodríguez Fernández, R. y Santamaría, G. 2005. Hoja Geológica 3169-I, Rodeo. Provincia de San Juan. Instituto de Geología y Recursos Minerales. Servicio Geológico Minero Argentino. Boletín 272, 47 p. Buenos Aires.

Castro, C. E. 1991. Geología del Batolito de Colangüil entre las quebradas de La Pancha y Agua Blanca (Análisis del mecanismo de emplazamiento). Departamento Iglesia, Provincia de San Juan. Universidad Nacional de San Juan, Facultad de Cs. Exactas, Físicas y Naturales. Tesis doctoral.

Furque, G. 1962. Perfil geológico de la Cordillera de Olivares, Iglesia, San Juan. Anales 1as. Jornadas Geol. Arg., 2 Geología, Buenos Aires, 79-88.

Gemuts, I., Little M. L. and Giudici, J. 1996. Precious and Base Metal Deposits in Argentina. SEG Newsletter 25, 7-14.

González, C. R. 1981. El Paleozoico superior marino de la República Argentina, Bioestratigrafía y Paleontología. Ameghiniana 18, 1/2, 51-65, Buenos Aires.

Gutiérrez, P. A. 1983. Geología del tramo medio de la Quebrada de Agua Negra, Departamento de Iglesia, provincia de San Juan. Trabajo Final de Licenciatura, (Inédito). Fac. Ciencias Exactas y Nat., Universidad Bs. As.

Grassi, J. I., Machuca, E., Rossa N., Mendoza N., Belvideri, I. and Manzanares, B. 1994. Estudio del potencial geológico-Minero del Área Mineralizada del Arroyo Tocota. Departamento Iglesia, San Juan, Argentina. Universidad Nacional de San Juan, Facultad de Cs. Exactas, Físicas y Naturales; inédito. CICITCA.

Hawkes, H. E. and Webb, J. S. 1962. Geochemistry in mineral exploration. Harper's Geoscience Series. New York.

Heredia, N., Rodríguez Fernández, L. R., Gallastegui, 
G., Busquets, P. and Colombo, F. 2002. Geological Setting of the Argentine Frontal Cordillera in the flat-slab segment $\left(30^{\circ} 00^{\prime}-31^{\circ} 30^{\prime}\right.$ 'S latitude). Journal of South American Earth Sciences 15: 79-99.

Hedenquist, J., Izawa, A, Arribas JR. A. and White, N. 1996. Epithermal gold deposits: Styles, characteristics and exploration. The Society of Resource Geology, Japan, Special Publication, 1.

Hoefs, J. 2009. Geoquímica de isótopos estables $\left(6^{a}\right.$ ed.). Berlín: Springer-Verlag. ISBN 978-3-54070703-5.

Kittl, E. and Bellio, N. 1946. Estudio geológico - económico de los yacimientos de arsénico de Tocota, departamento Iglesia, provincia de San Juan. Revista Minera. Tomo 17, No. 4, 73-104.

Lara, R., Grassi I., Martínez R. and Treo C. 1993-a. Geología, alteraciones y potencial minero del dique de brecha y vetas asociadas en la región de la quebrada de Tocota, Cordillera Frontal, San Juan. 12do Congreso Geológico Argentino - 2do Congreso Explor. de Hidrocarburos. Tomo 5: 150-158. Mendoza, Argentina.

Lara, R., Puigdomenech, H. and Taner, M. 1993-b. Mineralización de metales preciosos $(\mathrm{Au}-\mathrm{Ag})$ y de base (Cu-Mo) en un sector de la quebrada del Arroyo Chita, Departamento Iglesia - San Juan. 12do Congreso Geológico Argentino - 2do Congreso Explor. de Hidrocarburos. Tomo 5: 131-139. Mendoza, Argentina.

Llambías, E. J. and Malvicini, L. 1966. Metalogénesis asociada a los plutones graníticos de la Cordillera Frontal, entre quebrada de Agua Negra y Río Castaño, San Juan. Revista de la Asociación Geológica Argentina, Tomo 21, No. 4, 239 - 261.

Llambías, E. J. and Malvicini, L. 1969. The Geology and Genesis of the Bi-Cu Mineralized Breccia Pipe, San Francisco de Los Andes, San Juan, Argentina. Economic Geology, Vol. 64, pp. 271 - 286.

Llambías, E. J., Sato, A. M., Puigdomenech, H. and Castro, C. E. 1987. Neopaleozoic batholith and their tectonic setting. Frontal Range of Argentina between $29^{\circ}$ and $31^{\circ} \mathrm{S}$. Congreso Geológico Argentino $N^{\circ} 10$, Symposium Circum Pacific and Phanerozoic Granites, Actas, Vol. 4, 92-95. San Miguel de Tucumán.

Llambías, E. J. and Sato, A. M. 1990. El Batolito de Colangüil $\left(29-31^{\circ} \mathrm{S}\right)$, Cordillera Frontal de Argentina; estructura y marco tectónico. Revista Geológica de Chile, vol. 17, No. 1, 89-108. Servicio Nacional de Geología y Minería. Santiago, Chile.

Malvicini, L. and Caminos, R. 1994. La Época Metalogenética Gondwánica en la República Argentina. 7 mo Congreso Geológico Chileno, Actas Volumen 2, 848-852.

Mas, M. A. and Olivares, L. A. 1997. Estudio geológico y tratamiento mineralúrgico del mineral de la mina San Roque, Calingasta, San Juan. Revista Ciencias, Facultad de Ciencias Exactas, Físicas y Naturales - UNSJ.

Meyer, C. and Hemley, J. J. 1967. Wall Rock Alteration.
Geochemistry of Hydrothermal Ore Deposits, Primera Edición, Hubert L. Barnes (ed.), Holt, Rinehart and Winston Inc. Publication, 166-235.

Pelichotti, R. and Rojo, C. 1979. Estudio Geológico-Minero de los Yacimientos del Flanco Oriental de Cordillera Frontal. Servicio Minero Nacional, Argentina - Plan San Juan (Inédito).

Polanski, J. 1958. El bloque varíscico de la Cordillera Frontal de Mendoza. Asociación Geológica Argentina, Revista 12 (3): 165-196. Buenos Aires.

Polanski, J. 1970. Carbónico y Pérmico en la Argentina. Editorial Eudeba, $2^{\circ}$ Ed. 1978, 216 pág., Universidad de Buenos Aires.

Poma, S., Ramos, A., Litvak, V. D., Quenardelle, S., Maisonnave, E. B. and Díaz, I. 2017. Southern Central Andes Neogene magmatism over the Pampean Flat Slab: implications on crustal and slab melts contribution to magma generation in Precordillera, Western Argentina. Andean Geology 44 (3): 249274. www.andeangeology.cl

Rabbia, O., Hernández, L. and Wetten, A. 1996. Rutilos portadores de $\mathrm{Fe}$, Sc y W en el distrito minero Tocota. 3ra Reunión de Rocas Máficas y Ultramáficas y 3ra Reunión de Mineralogía y Metalogenia, pp.: 203-207. La Plata.

Ramos, V. A. 1988. The tectonic of the Central Andes: $30^{\circ}$ to $33^{\circ} \mathrm{S}$ latitude. Processes in Continental Litospheric Deformation, S. Clark and D. Burchfiel (Eds.). Geol. Soc. Amer., Spec. Paper, 218, 31-54.

Ramos, V. A. 1999. Las Provincias Geológicas del Territorio Argentino. Instituto de Geología y Recursos Minerales. Anales 29 (3): 41 - 96, Buenos Aires.

Reynolds, T. J. and Goldstein, R. H. 1995. Systematics of Fluid Inclusions in Diagenetic Minerals. SEPM short Course 31. USA.

Rodríguez Fernández, L. R., Heredia, N., Marin, G., Quesada, C. Robador, A., Ragona, D. and Cardó, R. 1996-a. Tectonoestratigrafía y estructura de los andes argentinos, entre los $30^{\circ} 30^{\prime}$ y $31^{\circ} 00^{\prime}$ de Latitud S. 13er Congreso Geológico Argentino y 3er Congreso de Exploración de Hidrocarburos, Actas 2: 111 - 124.

Rodríguez Fernández, L. R., Heredia, N., Gallastegui, G., Quesada, C., Robador, A., Marín, G., Cardó, D. R. 1996-b. Texto explicativo de la Carta Geológica No. 3169-14 a escala 1:100,000 (Paraje de Castaño Viejo). Servicio Geológico y Minero Argentino, pp. 145 (unpublished).

Rodríguez Fernández, L. R., Heredia, N., Gallastegui, G., Busquets, P., Colombo, F. 2002. The Argentine Frontal Cordillera between $30^{\circ} 00^{\prime}$ and $31^{\circ} 30^{\prime}$ S latitude: polycyclic structure and tectonic evolution. Sociedad Geológica de España. Geogaceta, 32: 167-170.

Rollinson, H. 1994. Using geochemical Data: Evaluation, Presentation, Interpretation. Chapters 4-3, 7-5. Longman Scientific \& Technical, pp: 133-142, 303315.

Sato, Ana María. 1989. Caracterización petrológica del 
plutón granítico de Chita, Departamento Iglesia, Pcia. de San Juan. Facultad de Ciencias Exactas y Naturales. Universidad de Buenos Aires. http:// digital.bl.fcen.uba.ar/Download/Tesis/Tesis_2250_ Sato.pdf.

Sato, A.M. and Llambías, E. J. 1993. El Grupo Choiyoi, Provincia de San Juan: equivalente efusivo del Batolito de Colangüil. 12do Congreso Geológico Argentino y 2do Congreso de Exploración de Hidrocarburos. Actas T. 4: (156-165).

Sato, A.M., Llambías, E. J., Basei, M.A.S., Castro, C.E. 2015. Three stages in the Late Paleozoic to Triassic magmatism of southwestern Gondwana and the relationships with the volcanogenic events in coeval basins. Journal of South American Earth Sciences 63 (2015) 48-69.

Seguí, C. 1987. Estudio geológico minero y evaluación preliminar de la mina Krammer, distrito Tocota, dpto. Iglesia, Provincia de San Juan. Trabajo Final de Licenciatura, (Inédito), F.C.E.F. y N.-U.N.S.J.

Wetten, F. 1953. Estudio geológico-económico de los yacimientos de wolfram de Arrequintín, departamento Iglesia, provincia de San Juan. (Inédito). Universidad Nacional de Cuyo.

Wetten, A. F., 1995. Distrito minero Tocota, San Juan, Argentina: aporte al conocimiento de su geología y mineralización. Quinto Congreso Nacional de Geología Económica y Simposio de Metalogenia Andina, 60-68. San Juan, Argentina. 1997. Procesamiento de imágenes Land- sat TM, tendiente a la caracterización geológica del borde oriental de la Cordillera Frontal, entre las quebradas de Los Frijoles y del Chorrillo. San Juan, Argentina. Cuarto Simposio Argentino de Teledetección. San Juan, Argentina.

1998-a. Los filones hidrotermales de Tocota, provincia de San Juan. Datos termométricos e isotópicos. IV Reunión de Mineralogía y Metalogénesis, 279-283. Bahía Blanca, 23 al 25/09/98.

1998-b. Aspectos Metalogenéticos del área comprendida entre el Distrito Minero Tocota y los 3050' L.S., provincia de San Juan, Argentina. Departamento de Postgrado, Facultad de Cs. Ex., Fís. y Nat., UNSJ. Tesis doctoral. Inédito.

1999. Distrito Minero Tocota, San Juan, Argentina. Recursos Minerales de la República Argentina, Instituto de Geología y Recursos Minerales SEGEMAR, Anales 35: 821-827, Buenos Aires.

2005. Andesita Cerro Bola: nueva unidad vinculada al magmatismo Mioceno de La Cordillera de Olivares, San Juan, Argentina (30³5'S; 69³0'O). Revista de la Asociación Geológica Argentina. 60, 3- 8 .

2020. Modelo tentativo de depositación metalífera en la zona de La Fragüita, extremo sur del batolito de Colangüil, Calingasta, San Juan. En preparación.

Whitney, D. L. and Evans, B. W. 2010. Abbreviations for names of rock-forming minerals. American Mineralogist, Volume 95, 185-187.

Recibido: julio 2019

Revisado: noviembre 2019

Aceptado: enero 2020

Publicado: marzo 2021 
